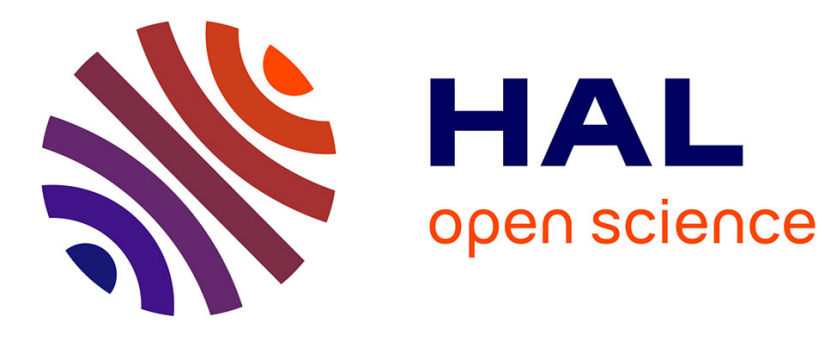

\title{
Notch1 switches progenitor competence in inducing medulloblastoma
}

Claudio Ballabio, Matteo Gianesello, Chiara Lago, Konstantin Okonechnikov, Marica Anderle, Giuseppe Aiello, Francesco Antonica, Tingting Zhang, Francesca Gianno, Felice Giangaspero, et al.

\section{To cite this version:}

Claudio Ballabio, Matteo Gianesello, Chiara Lago, Konstantin Okonechnikov, Marica Anderle, et al.. Notch1 switches progenitor competence in inducing medulloblastoma. Science Advances , 2021, 7 (26), pp.eabd2781. 10.1126/sciadv.abd2781 . hal-03272112

\section{HAL Id: hal-03272112 https://hal.sorbonne-universite.fr/hal-03272112}

Submitted on 28 Jun 2021

HAL is a multi-disciplinary open access archive for the deposit and dissemination of scientific research documents, whether they are published or not. The documents may come from teaching and research institutions in France or abroad, or from public or private research centers.
L'archive ouverte pluridisciplinaire HAL, est destinée au dépôt et à la diffusion de documents scientifiques de niveau recherche, publiés ou non, émanant des établissements d'enseignement et de recherche français ou étrangers, des laboratoires publics ou privés. 


\section{Notch1 switches progenitor competence in inducing medulloblastoma}

\author{
Claudio Ballabio ${ }^{1 \dagger}$, Matteo Gianesello ${ }^{1 \dagger}$, Chiara Lago ${ }^{1}$, Konstantin Okonechnikov ${ }^{2,3}$, \\ Marica Anderle ${ }^{1}$, Giuseppe Aiello ${ }^{1}$, Francesco Antonica ${ }^{1}$, Tingting Zhang ${ }^{4}$, Francesca Gianno ${ }^{5,6}$, \\ Felice Giangaspero ${ }^{5,6}$, Bassem A. Hassan ${ }^{4}$, Stefan M. Pfister ${ }^{2,3,7}$, Luca Tiberi ${ }^{1 *}$
}

\begin{abstract}
The identity of the cell of origin is a key determinant of cancer subtype, progression, and prognosis. Group 3 medulloblastoma (MB) is a malignant childhood brain cancer with poor prognosis and few candidates as putative cell of origin. We overexpressed the group $3 \mathrm{MB}$ genetic drivers MYC and Gfi1 in different candidate cells of origin in the postnatal mouse cerebellum. We found that $\mathrm{S} 100 \mathrm{~b}^{+}$cells are competent to initiate group $3 \mathrm{MB}$, and we observed that $\mathrm{S} 100 \mathrm{~b}^{+}$cells have higher levels of Notch 1 pathway activity compared to Math $1^{+}$cells. We found that additional activation of Notch 1 in Math $1^{+}$and Sox $2^{+}$cells was sufficient to induce group 3 MB upon MYC/Gfi1 expression. Together, our data suggest that the Notch 1 pathway plays a critical role in group $3 \mathrm{MB}$ initiation.
\end{abstract}

Copyright @ 2021

The Authors, some rights reserved; exclusive licensee American Association for the Advancement of Science. No claim to original U.S. Government Works. Distributed under a Creative Commons Attribution NonCommercial License 4.0 (CC BY-NC).

\section{INTRODUCTION}

Defining the cancer cell of origin can be critical for understanding the first steps of cancer development and finding the signals required for transformation $(1,2)$. The identity of certain classes of tumors seems to be more strongly related to the cell of origin than to the oncogenic insult that induces malignant transformation. For example, in brain tumors, concurrent inactivation of Trp53, Nf1, and Pten in neural progenitor cells or oligodendrocyte progenitors triggers the development of different subtypes of glioblastoma with distinct gene expression profiles $(3,4)$. $B C R-A B L$ (breakpoint cluster region-Abelson kinase fusion gene) also provides an interesting example of an oncogene that produces different tumors depending on the cell in which it is expressed (5). These studies suggest that the transcriptional context of the cell of origin can determine the identity of the tumor. By contrast, in some cases, certain driver mutations rather than the cell of origin mainly define the tumor profile. Activation of Hedgehog signaling in neural stem cells, granule neural precursors, or postmitotic granule neurons leads to development of aggressive medulloblastomas (MBs) with similar molecular profiles $(6-8)$. Nevertheless, it remains partially unclear what the specific determinants of the cell of origin required for tumor initiation are, and whether these specific features could be activated by an oncogenic insult only. For instance, few progenitors in the mouse brain are able to generate group $3 \mathrm{MB}$, although several genetic mutations that able to generate this kind of tumors have been identified (9-12).

Group 3 is the most aggressive subtype of $\mathrm{MB}$, mainly affecting children younger than 10 years of age. Recently, single-cell RNA sequencing (scRNA-seq) studies allowed the comparison of human cerebellar tumors with transcriptional clusters in the developing

\footnotetext{
${ }^{1}$ Armenise-Harvard Laboratory of Brain Cancer, Department CIBIO, University of Trento, Via Sommarive 9, 38123 Trento, Italy. ${ }^{2}$ Hopp Children's Cancer Center Heidelberg (KiTZ), Heidelberg, Germany. ${ }^{3}$ Division of Pediatric Neurooncology, German Cancer Research Center and German Cancer Consortium, Heidelberg, Germany. ${ }^{4}$ Paris Brain Institute-Institut du Cerveau, Sorbonne Université, Inserm, CNRS, Hôpital Pitié-Salpêtrière, 8, Paris, France. ${ }^{5}$ Dept. of Radiologic, Oncologic and Anatomo Pathological Sciences, University Sapienza of Rome, Rome, Italy. ${ }^{6}$ RCCS Neuromed, Pozzilli, Isernia, Italy. ${ }^{7}$ Department of Pediatric Hematology and Oncology, Heidelberg University Hospital, Heidelberg, Germany.

*Corresponding author. Email: luca.tiberi@unitn.it

†These authors contributed equally to this work.
}

murine cerebellum. Analysis of human group $3 \mathrm{MB}$ revealed the presence of different transcriptional clusters within the tumor, resembling granule neuron precursors (GNPs), unipolar brush cells (UBCs), Purkinje cells, and GABAergic interneuron lineages during normal development $(13,14)$. This suggested that early uncommitted human cerebellar stem cells might represent a putative group $3 \mathrm{MB}$ cell of origin (14).

The human cerebellum contains $80 \%$ of all brain neurons and has a 750-fold larger surface area, increased neuronal numbers, altered neuronal subtype ratios, and increased folia complexity compared to the mouse cerebellum $(15,16)$. Human cerebellar development begins 30 days after conception and is thought to be completed by the age of 2 years (15). Human cerebellar volume increases fivefold between 22 postconception weeks (PCW) and birth, and it becomes highly foliated during the third trimester [ 24 to 40 gestational weeks (GW)] (15). Granule cell progenitor proliferation peaks during this period, and it is accompanied by increased external granule layer (EGL) thickness. In mice, cerebellar growth and foliation are driven by granule cell progenitor proliferation between postnatal day 1 (P1) and P14, with deficient proliferation causing EGL thinning (17). Hence, the postnatal development of the mouse cerebellum resembles key aspects of human embryonic development. For this reason, the cell of origin of group $3 \mathrm{MB}$ should also be studied during postnatal mouse cerebellar development. MB mouse models have been developed by postnatally deregulating Myc and Trp53 ex vivo in Math $1^{+}$GNPs or in $\mathrm{CD}_{133^{+}}$stem cells $(11,12,18)$. It has also been demonstrated that $\mathrm{CD}_{133^{+}}$cerebellar stem cells and GNPs are able to give rise to group $3 \mathrm{MB}$ upon ex vivo enforced expression of $M y c$ and Gfil or $M y c$ and $G f i 1 b(10,19,20)$. Furthermore, we have recently demonstrated that MYC and Gfil induce group $3 \mathrm{MB}$ when co-overexpressed in human brain organoids (9). Moreover, Sox $2^{+}$astrocyte progenitors (upon $M y c$ overexpression ex vivo) have been proposed to give rise to group $3 \mathrm{MB}$ in the postnatal developing cerebellum (21). Notably, whether MYC and Gfil induce group $3 \mathrm{MB}$ in specific progenitor populations has never been tested in vivo, during embryonic or postnatal cerebellum development. In addition, the molecular features that render a cerebellar progenitor competent for group $3 \mathrm{MB}$ development are still unknown. 


\section{RESULTS}

\section{$\mathbf{S 1 0 0 b}^{+}$cells are competent to induce group $3 \mathrm{MB}$}

To modify mouse cerebellar cells directly in vivo, we stably transfected $\mathrm{P} 0$ mouse cerebella exploiting the piggyBac transposon system. We were able to target different cell populations in the developing cerebellum, such as $\operatorname{Pax}_{6}^{+}$, Sox $2^{+}$, Sox $9^{+}$, and Calbindin ${ }^{+}$cells (fig. S1, A to D) (9). To investigate which postnatal progenitors/cells are competent to potentially give rise to group $3 \mathrm{MB}$, we used mice expressing creER recombinase in GNPs (Math1-creER, 24 mice) (22), in glial cells progenitors (Sox2-creER, 7 mice) (23), Purkinje cells, GABAergic interneurons, and glial cells (Ascl1-creER, 24 mice) (Fig. 1A and fig. S1E) (24). We crossed these mice with R26-loxP$S T O P-l o x P-M y c$ (R26-LSL-Myc) transgenic mice conditionally expressing MYC under the control of the creER recombinase, and we stably transfected the cerebella at $\mathrm{P} 0$ with piggyBac vectors expressing Gfil (pPB-CAG-Gfi1). In parallel, we transfected the cerebella of mice bearing creER recombinase with piggyBac vectors expressing both MYC and Gfil under the control of a loxP-STOP-loxP cassette (pPB-LSL-MYC and pPB-LSL-Gfi1) at P0 (Fig. 1A). Subsequently, we induced the creER-dependent removal of the LSL cassette by injecting tamoxifen (TMX) at different time points (table S1; we considered only mice with transfected cells). To further identify which progenitors are competent to give rise to group $3 \mathrm{MB}$, we also transfected PPB-LSL-MYC and pPB-LSL-Gfil vectors together with plasmids expressing the cre recombinase under the control of Tbr2 (UBCs), Sox2, Math1, or S100b (astrocytic and extra-astrocytic expression in human brain) (25) regulatory elements (Fig. 1B and table S1). Notably, we obtained tumors only when MYC and Gfil expression was driven by $S 100 b$ promoter (3 of 16, from two different litters; Fig. 1C). These tumors showed few $\mathrm{S}_{100 \mathrm{~b}^{+}}$cells (Fig. 1D), consistently with the observation that the tumor phenotype not always resembles its cell of origin $(26,27)$. In addition, these tumors were $\mathrm{pH}^{+}$, showed few glial fibrillary acidic protein-positive $\left(\mathrm{GFAP}^{+}\right)$cells, and were also positive for the group 3 -specific marker natriuretic peptide receptor 3 (NPR3) (Fig. 1E and fig. S1, F and G). Sox2-creER;R26-LSL-Myc mice developed choroid plexus carcinoma (CPC) 1 month after TMX injection (6 of 6; Fig. 1F) as already published $(28,29)$. We did not detect MB formation with any of the other promoters, but we observed Venus $^{+}$cells 75 days after injection (Fig. 1, G and H, and fig. S1, $\mathrm{H}$ and I). We checked the expression of MYC and Gfil by immunofluorescence (fig. S1, J to L). We were able to detect the expression of MYC in the CPC developed by Sox2-creER;R26-LSL-Myc transgenic mice injected with TMX at P2 (fig. S1J). The expression of both Gfil and MYC was also observed by immunofluorescence in P7 CD1 mouse cerebella transfected at P0 with pMath1-cre+ pPB-LSL-MYC + pPB-LSL-Gfi1 (fig. S1, K and L).

Because the $S 100 b$ promoter was able to drive cre expression in cells competent to develop group $3 \mathrm{MB}$, we investigated the identity of these cells. As shown in fig. S2A, S100b cells are present in the mouse cerebellum at P0. In addition, we could detect Venus ${ }^{+} /$ $\mathrm{S}_{100 \mathrm{~b}^{+}}$cells 4 days after transfection with pS100b-cre + pPB-LSLVenus, thus confirming that our promoter recapitulates endogenous S100b expression (Fig. 2, A and B). Furthermore, S100b promoter drives Venus expression not only in the ventricular zone (VZ) but also in the white matter (WM), internal granule layer (IGL), molecular layer (ML), and EGL, and most of those cells are positive for Sox 2 and GFAP (glial cells; Fig. 2, C and D). Because the Sox2 promoter is not able to render postnatal cells competent for group $3 \mathrm{MB}$ development, we investigated the presence of $\mathrm{S} 00 \mathrm{~b}^{+}\left(\mathrm{Venus}^{+}\right)$and Sox $2^{-}$cells (Fig. 2, D and E, and fig. S2, B and C). We observed that $34.8 \pm 7.7 \%$ (mean \pm SEM, $n=7$ brains) of S100b-cre ${ }^{+}$cells are Sox $2^{-} 4$ days after transfection, with a small subset being Sox $2^{-}$/ $\mathrm{Nestin}^{+}$(Fig. 2D). We then characterized which cells are produced by $\mathrm{S} 100 \mathrm{~b}-\mathrm{cre}^{+}$cells by performing lineage tracing experiments. Thirty days after transfection, we observed ependymal cells (Fig. 2F), glial cells (fig. S2D), oligodendrocytes (Fig. 2G), Bergmann glia (Fig. $2 \mathrm{H}$ ), and $\mathrm{S} 100 \mathrm{~b}^{+}$cells (Fig. 2I) that derive from S100b-cre ${ }^{+}$ cells transfected at P0. Hence, the population of S100b-cre ${ }^{+}$cells at $\mathrm{P} 0$ is able to generate several cerebellar populations, notably different types of glial cells. To study the first step of S100b cell transformation, we performed lineage tracing of S100b-cre ${ }^{+}$cells that start to stably express MYC and Gfil starting from P0. As shown in Fig. 2 ( $\mathrm{J}$ to $\mathrm{M}$ ), after 10 days, we observed small clusters of Venus ${ }^{+}$ cells, having a homogeneous round morphology that is different from cells not expressing MYC and Gfi1 (Fig. 2E and fig. S2, B and C). Furthermore, these cell clusters are mainly GFAP ${ }^{-}$and S100b (Fig. 2, J and M), with few Sox $2^{+}$and Sox $9^{+}$cells (Fig. 2, K and L). We did not detect any cluster formation with other promoters driving cre expression (Fig. 1, G and H, and fig. S1, H and I). Because $\mathrm{S} 100 \mathrm{~b}^{+}$cells are able to generate group $3 \mathrm{MB}$ postnatally, we tested whether $\mathrm{S} 100 \mathrm{~b}^{+}$cells might be competent to give rise to $\mathrm{MB}$ also during embryonic development. We first confirmed the embryonic expression of S100b in the cerebellar VZ (fig. S2E) (30), and then we electroporated in utero pPB-LSL-MYC + pPB-LSL-Gfil together with pS100b-cre at embryonic day 15.5 (E15.5) (fig. S2F). We observed formation of tumors in 3 of 12 electroporated mice (fig. S2G) that were positive for the group 3-specific marker NPR3 (fig. $\mathrm{S} 2 \mathrm{H}$ ).

\section{Human S100B ${ }^{+}$cells are competent to induce group 3 MB}

To test whether $\mathrm{S} 00 \mathrm{~B}^{+}$cells are also present during human cerebellar development, we performed histological analysis of S100B in human tissues. As shown in Fig. 3 (A and B), $\mathrm{S} 00 \mathrm{~B}^{+}$cells are present in the human cerebellum at 22 and $39 \mathrm{GW}$ in EGL, IGL, and ML. We could also detect a few $\mathrm{S}_{100 \mathrm{~B}^{+}}$cells in human group $3 \mathrm{MB}$ samples (fig. S3A). On the basis of these results, we tested whether human $\mathrm{S}_{100 \mathrm{~B}^{+}}$cells are competent to generate $\mathrm{MB}$ in human cerebellar organoids. We have recently shown that MYC and Gfil overexpression in human cerebellar organoids induces group $3 \mathrm{MB}$ with a methylation profile similar to human patients (9). Therefore, we electroporated human induced pluripotent stem cell (iPSC)-derived cerebellar organoids $(9,31)$ with pPB-LSL-Venus and pS100b-cre or pSox2-cre at day 35 to target $\mathrm{S}_{100 \mathrm{~B}^{+}}$and $\mathrm{SOX} 2^{+}$cells when these cerebellar progenitors are present (fig. S3, B to D) $(9,31)$. Unfortunately, we were unable to specifically target GNPs in human cerebellar organoids, as reliable human $A T O H 1$ regulatory sequences are lacking. Next, we also electroporated pPB-LSL-MYC + pPB-LSL-Gfi1 together with pS100b-cre or pSox2-cre. As shown in Fig. 3 (C and D), MYC and Gfil expression in S100B-cre ${ }^{+}$cells induced formation of clusters of cells in $12.5 \%$ of electroporated organoids $(n=40)$, as we previously observed (9). MYC and Gfil overexpression in SOX2-cre ${ }^{+}$cells did not induce cell cluster formation (0 of 40) (Fig. 3, C and D). Furthermore, we observed clusters of proliferating cell nuclear antigen-positive $\left(\mathrm{PCNA}^{+}\right)$cells using the $S 100 B$ promoter, suggesting that $M Y C$ and Gfil overexpression has an oncogenic potential in S100B-cre ${ }^{+}$cells also in human cerebellar organoids (Fig. 3E). 
A

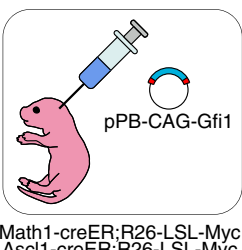

Math1-creER;R26-LSL-Myc
Ascl1-creER;R26-LSL-Myc

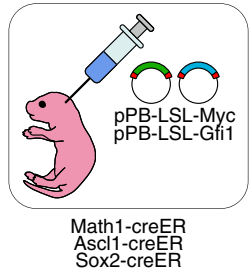

B

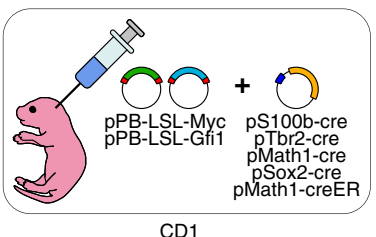

D

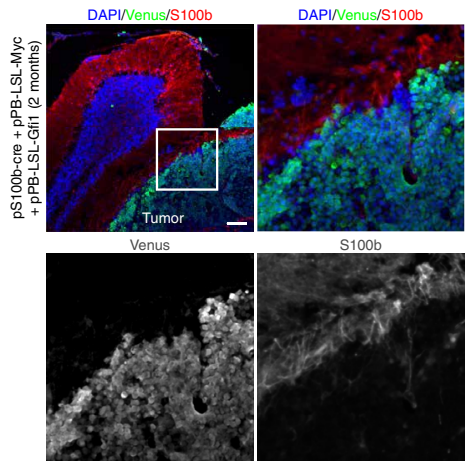

F

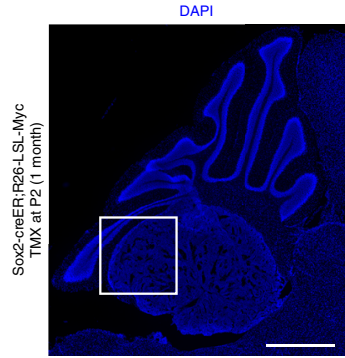

$\mathbf{F}^{\prime}$

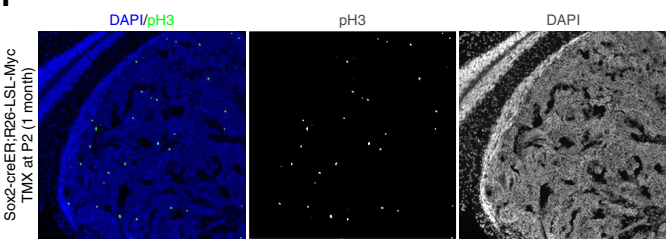

C

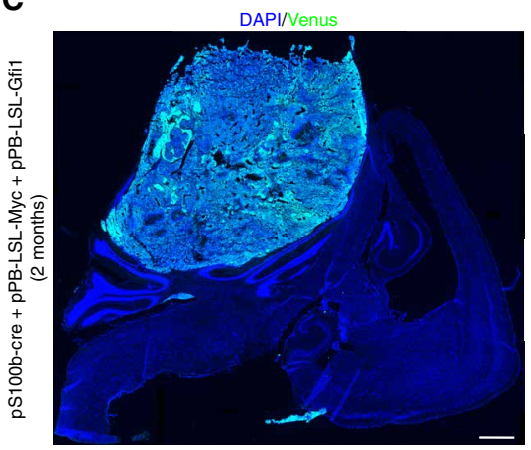

E
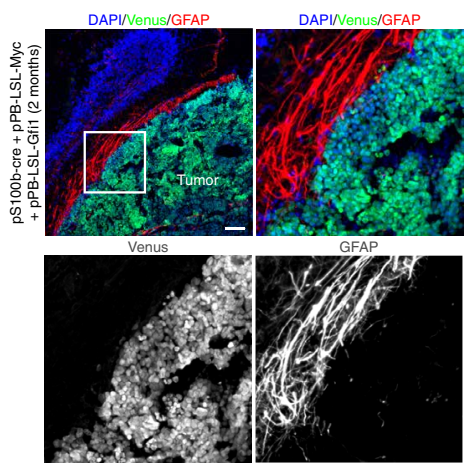

G

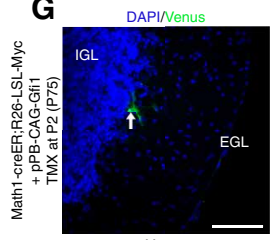

H
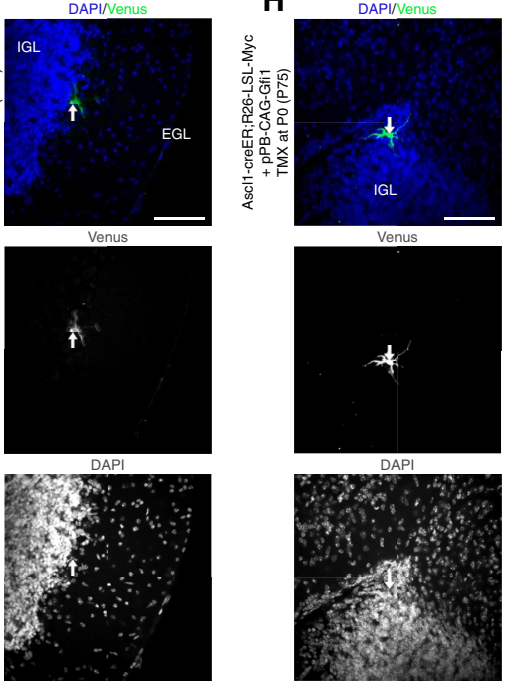

Fig. 1. Overexpression of MYC and Gfi1 in postnatal S100b ${ }^{+}$cerebellar cells induces $\mathbf{M B}$. (A and B) Schematic representation of in vivo transfection experiments to overexpress MYC and Gfi1 in different postnatal cerebellar cell populations. (C) DAPI (4',6-diamidino-2-phenylindole) staining and Venus immunofluorescence of sagittal brain section of CD1 mouse 2 months after transfection with pPBase + pS100b-cre + pPB-LSL-MYC + pPB-LSL-Gfi1 + pPB-LSL-Venus at P0. (D and E) Confocal images of Venus and S100b (D) and Venus and GFAP (E) immunofluorescence of tumors in CD1 mice 2 months after transfection with pPBase + pS100b-cre + pPB-LSL-Myc + pPBLSL-Gfi1 + pPB-LSL-Venus at P0. The white squares in (D) and (E) mark the regions shown at higher magnification. (F) DAPI staining and pH3 immunofluorescence of sagittal brain section of Sox2-creER;R26-LSL-Myc mouse 1 month after TMX injection at P2. The white square in (F) marks the region shown in ( $F^{\prime}$ ). (G and $\mathbf{H}$ ) DAPI staining and Venus immunofluorescence of sagittal brain sections of Math1-creER;R26-LSL-Myc mouse (G) or Ascl1-creER;R26-LSL-Myc mouse (H) 2.5 months after transfection with pPBase + pPB-Gfi1 + pPB-Venus at P0 and TMX injection at P2 (G) or P0 (H). Arrows point to Venus ${ }^{+}$cells. Scale bars, $1 \mathrm{~mm}(\mathrm{C}$ and F) and $100 \mu \mathrm{m}(\mathrm{D}, \mathrm{E}, \mathrm{G}$, and $\mathrm{H})$. IGL, internal granule layer; EGL, external granule layer. 

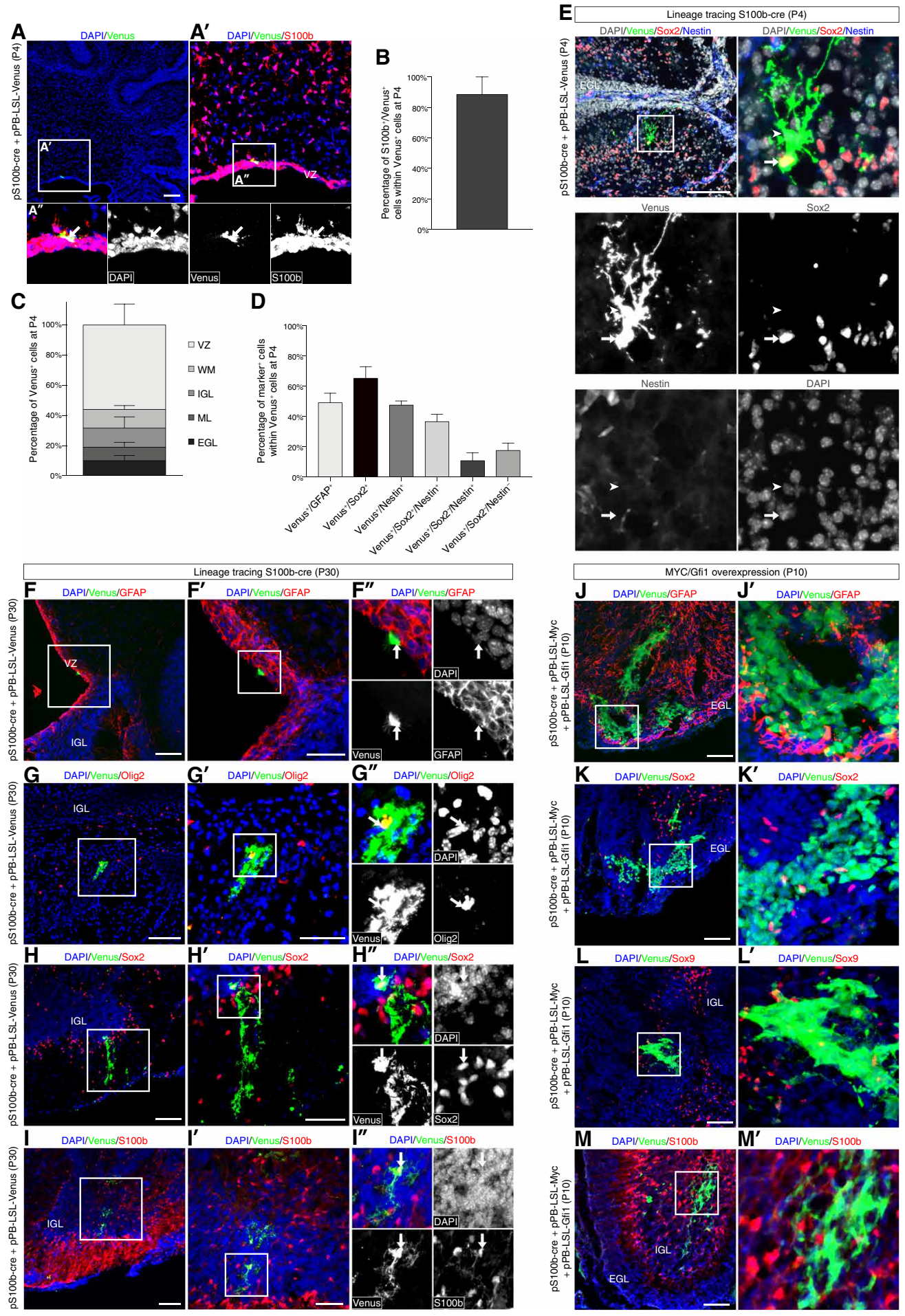

Fig. 2. Lineage tracing of $\mathbf{S 1 0 0 b}-$ cre $^{+}$cells in postnatal CD1 mouse cerebellum. (A to E) Lineage tracing in P4 cerebellum transfected with pPBase $+p S 100 b-c r e+p P B-$ LSL-Venus at P0. (A) Immunofluorescence of Venus and S100b. (A and $A^{\prime}$ ) Higher magnifications in ( $A^{\prime}$ ) and (A"). The arrow marks a S100 ${ }^{+} /$Venus $^{+}$cell. (B) Quantification of $\mathrm{S} 100 \mathrm{~b}^{+} /$Venus $^{+}$cells within Venus ${ }^{+}$cells. (C) Quantification of Venus ${ }^{+}$cells within different regions. VZ, ventricular zone; white matter, WM; ML. molecular layer. (D) Quantification of Venus ${ }^{+} / \mathrm{GFAP}^{+}$, Venus ${ }^{+} / \mathrm{Sox}^{+}$, Venus ${ }^{+} /$Nestin $^{+}$, Venus $^{+} / \mathrm{Sox}^{+} / \mathrm{Nestin}^{+}$, Venus $^{+} / \mathrm{Sox}^{-} / \mathrm{Nestin}^{+}$, and Venus ${ }^{+} / \mathrm{Sox}^{-} / \mathrm{Nestin}^{-}$cells within Venus $^{+}$cells. (E) Immunofluorescence of Venus, Sox2, and Nestin. The white square marks the region shown at higher magnification. The arrow marks a Venus ${ }^{+} /$Sox $^{+}$cell; the arrowhead marks a Venus ${ }^{+} /$Sox2 $2^{-}$cell. (F to I) Immunofluorescence of Venus with GFAP (F), Olig2 (G), Sox2 (H), and S100b (I) in P30 cerebellum transfected with pPBase + pS100b-cre + pPB-LSL-Venus at P0. ( $F$ to I and $F^{\prime}$ to $\left.I^{\prime}\right)$ Higher magnifications in $\left(F^{\prime}\right)$ to $\left(I^{\prime}\right)$ and $\left(F^{\prime \prime}\right)$ to $\left(I^{\prime \prime}\right)$. Arrows mark double-positive cells. (J to $\left.M\right) ~ I m m u n o f l u o r e s c e n c e$ of Venus and GFAP (J), Sox2 (K), Sox9 (L), and S100b (M) in P10 cerebellum transfected with pPBase + pS100b-cre + pPB-LSL-MYC + pPB-LSL-Gfi1 + pPB-LSL-Venus at P0. ( $\mathrm{J}$ to $\mathrm{M}$ ) Higher magnifications in $\left(\mathrm{J}^{\prime}\right)$ to $\left(\mathrm{M}^{\prime}\right)$. Confocal images scale bars, $100 \mu \mathrm{m}$ (A and $\mathrm{E}$ to $\mathrm{M}$ ) and $50 \mu \mathrm{m}$ in ( $\mathrm{F}^{\prime}$ to $\mathrm{I}^{\prime}$ ). Data in (B) to (D) presented as means + SEM. 
A

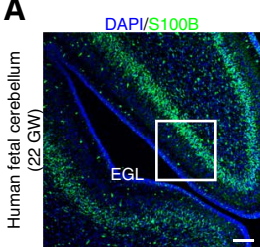

$\mathbf{A}^{\prime}$

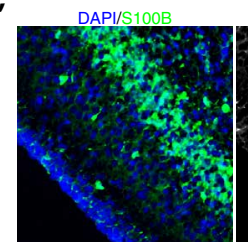

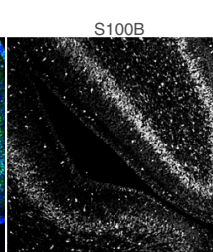

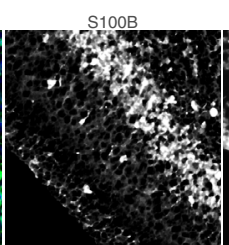

DAPI

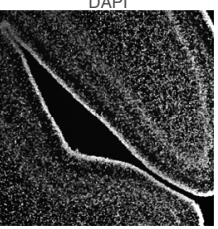

DAPI

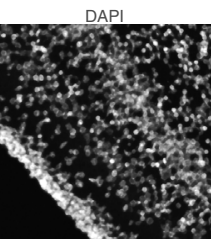

B

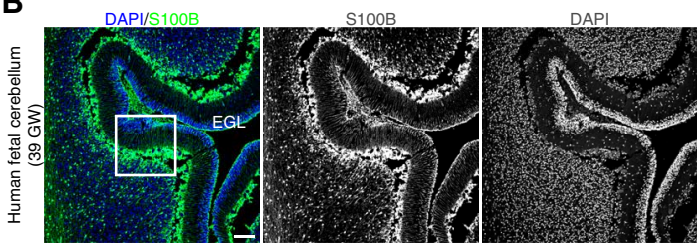

$\mathbf{B}^{\prime}$

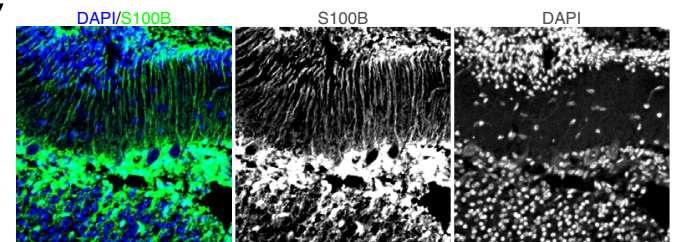

c
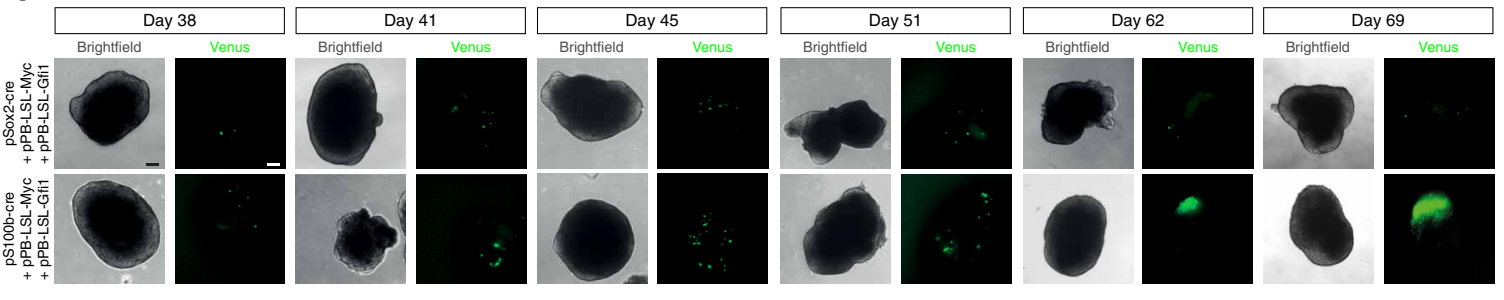

D

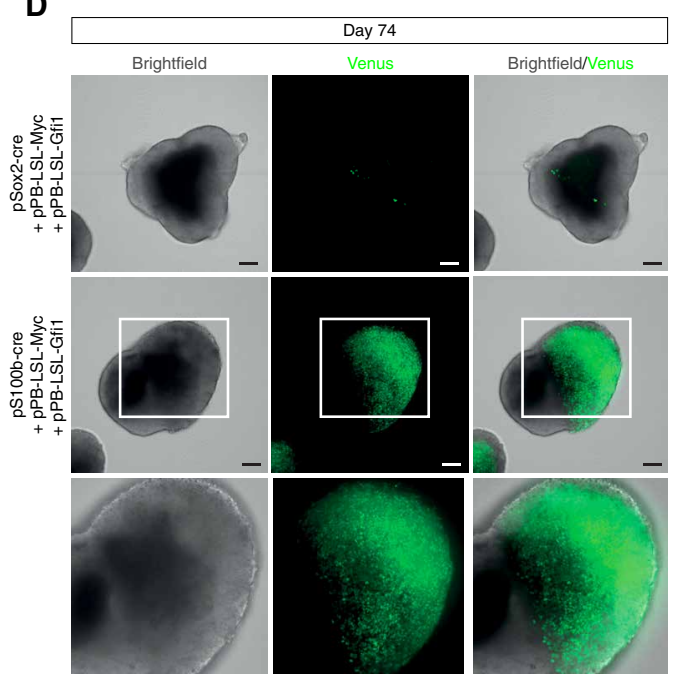

E
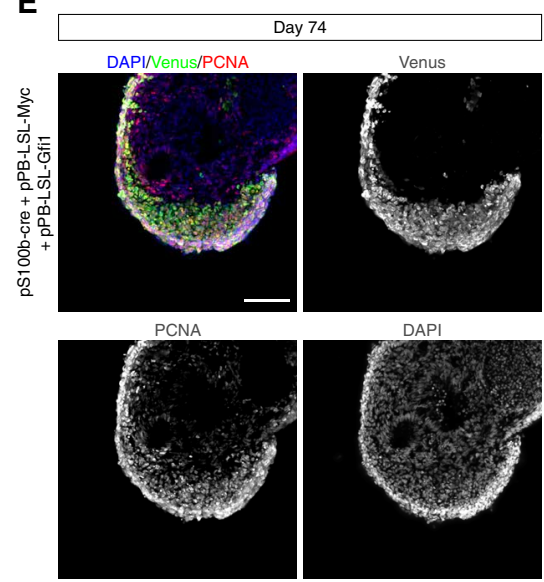

Fig. 3. Human S100B-cre ${ }^{+}$cells are responsive to MYC and Gfi1 overexpression. (A) Confocal images of S100B immunofluorescence of human fetal cerebellum at $22 \mathrm{GW}$. (B) Confocal images of S100B immunofluorescence of human fetal cerebellum at $39 \mathrm{GW}$. The white squares in (A) and (B) mark the regions shown at higher magnification in $\left(A^{\prime}\right)$ and $\left(B^{\prime}\right)$, respectively. $(C)$ Brightfield and fluorescence images of cerebellar organoids at different time points electroporated at day 35 with pPBase + pSox2cre + pPB-LSL-Gfi1 + pPB-LSL-MYC + pPB-LSL-Venus, or pPBase + pS100b-cre + pPB-LSL-Gfi1 + pPB-LSL-MYC + pPB-LSL-Venus. (D) Brightfield and fluorescence images of cerebellar organoids at 74 days, electroporated at day 35 with pPBase + pSox2-cre $+p P B-L S L-G f i 1+p P B-L S L-M Y C+p P B-L S L-V e n u s$ or pPBase $+p S 100 b-c r e+p P B-L S L-$ Gfi1 + pPB-LSL-MYC + pPB-LSL-Venus. The white squares mark the regions shown at higher magnification. (E) Confocal images of Venus and PCNA immunofluorescence of cerebellar organoids at day 74, electroporated at day 35 with pPBase + pS100b-cre + pPB-LSL-Gfi1 + pPB-LSL-MYC + pPB-LSL-Venus. Scale bars, $100 \mu$ m (A to E).

\section{Notch 1 activation makes Math $1^{+}$progenitors competent to induce group $3 \mathrm{MB}$}

On the basis of our data, we speculated that $\mathrm{S} 100 \mathrm{~b}^{+}$cells should have specific features/pathways that are present to a lesser extent in postnatal Math ${ }^{+}$, Ascl1 ${ }^{+}$, and Sox $2^{+}$cells. It has been found that Notch signaling regulates fate decisions of early mouse cerebellar progenitors $(32,33)$. In particular, Sox $2^{+}$progenitors at $\mathrm{E} 9.5$ have high Notch1 pathway levels and are competent to give rise to $\mathrm{Ascll}^{+}$ and Math $1^{+}$progenitors (33). We tried to target these Sox $2^{+}$early progenitors by conditionally overexpressing Myc at E9.5 and at E13.5 (Sox2-creER;R26-LSL-Myc mouse), but we were not able to obtain live pups, possibly due to a widespread Sox 2 expression during mouse development $(n=2$ pregnant females administered with TMX at E9.5; $n=2$ pregnant females administered with TMX at E13.5). Notably, these early Sox $2^{+}$progenitors do not generate the Sox $2^{+}$cells residing in the postnatal cerebellum (Sox2-creER;R26-LSL-tdTomato, TMX 
at E10.5; fig. S4A). Furthermore, embryonic Math $1^{+}$progenitors express low levels of Notch1 and Hes1/Hes 5 target genes, and Notch 1 pathway activation is able to repress Math1 expression, thus changing the fate of these progenitors (33). The Notch signaling pathway plays a critical role in central nervous system development, stem cell maintenance, and differentiation of cerebellar GNPs and modulates epithelial-to-mesenchymal transition; and its role in SHH MB is still controversial (34-37). Mutations in NOTCH signaling genes have been described in group $3 \mathrm{MB}(38)$, with especially elevated expression of NOTCH1 in spinal metastases (39).

On the basis of these data, we tested whether the Notch1 pathway plays a role in determining the competence of the different cerebellar progenitors to generate group $3 \mathrm{MB}$. Using available scRNA-seq data (40) from postnatal (P0 and P4) mouse cerebella, we verified the stable cell types assignment for the different cerebellar cell populations (Fig. 4A and fig. S4B). Further analyses on the scRNA-seq data indicated that $S 100 b$ is expressed in clusters assigned to the astrocytic lineage (which includes glial progenitors, oligodendrocytes, glia, and Bergmann glia; clusters $\beta$ and $\gamma$ ) and ciliated cells (cluster $\alpha$ ) (Fig. 4, A to D) (40) and is mostly mutually exclusive with the expression of Math1 (Fig. 4, E to G), especially in the granule neurons lineage. Therefore, we asked whether the expression of Notch pathway genes correlates with any cell lineage also in the postnatal cerebellar scRNA-seq data, as in the embryonic mouse cerebellum (33). As shown in Fig. 4 ( $\mathrm{H}$ to $\mathrm{P}$ ) and fig. S4 (C and D), we found that the

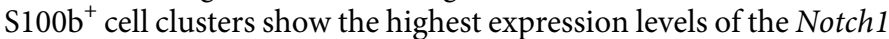
receptor and of Hes1/Hes5 target genes. On the other hand, postnatal Math $1^{+}$cells display lower levels of Notch pathway activation, similar to the Math $1^{+}$progenitors in the embryonic mouse cerebellum (33).

To confirm these data, we tested Notch activity using a wellknown reporter for Notch signaling. We used a plasmid that drives the expression of destabilized enhanced green fluorescent protein (d2EGFP) under the control of the Hes5 promoter (41). The promoter activity is dependent on Notch pathway activation and is restricted to neural stem cells in the mouse brain $(41,42)$. As shown in fig. S4 (E to G), we observed more d2EGFP expression in $\mathrm{S}_{100 \mathrm{~b}^{+}}$ cells compared to Math $1^{+}$progenitors, confirming that the Notch pathway is more active in $\mathrm{S}_{100 \mathrm{~b}^{+}}$cells.

Notably, we overexpressed the Notch1 constitutively active form (N1ICD) $(42,43)$ with $M Y C$ in postnatal mouse cerebellum and, together, they are sufficient to induce MB (fig. S5A). N1ICD and Gfil co-overexpression was not sufficient to generate tumor, highlighting the Notch and MYC relation in tumor formation (fig. S5A). To test whether the Notch pathway is also required for the formation of group $3 \mathrm{MB}$, we used the dominant negative forms of the Notch pathway components Maml1 (DN-Maml1) and Rbpj (DN-Rbpj) $(44,45)$. As shown in fig. S5B, we did not observe tumor formation upon overexpression in $\mathrm{S}_{100 \mathrm{~b}^{+}}$cells of DN-Maml1 or DN-Rbpj together with MYC/Gfi1, suggesting that the Notch pathway activation is required for group $3 \mathrm{MB}$ formation. On the other hand, we tested whether increasing Notch pathway activity could make Math $1^{+}$ cells competent to induce group $3 \mathrm{MB}$. To do so, we overexpressed N1ICD in Math $1^{+}$cells, which alone did not induce MB formation (Fig. 5A). Next, we co-overexpressed N1ICD with MYC and Gfil to induce group $3 \mathrm{MB}$ in Math $1^{+}$progenitors. As shown in Fig. 5 (B and C), stable N1ICD overexpression, together with MYC/Gfi1, in Math $1^{+}$ progenitors induces tumor formation in 13 of 14 mice (Fig. 5A). These tumors are $\mathrm{GFAP}^{-}, \mathrm{pH}^{+}$(fig. S5, C and D), and are comparable to human group $3 \mathrm{MB}$ and to previously published group
3 MB mouse models (MYC/Gfi1, MYC/Otx2, and MYC overexpression in Sox $2^{+}$progenitors; Fig. 5 , D and E) $(9,21)$. We compared the transcriptional profiles of tumors induced by N1ICD + MYC/Gfil in Math $1^{+}$cells and tumors induced by MYC/Gfil in $\mathrm{S}_{100 \mathrm{~b}^{+}}$cells with human $\mathrm{MB}$ samples classified according to the consensus subtypes (46). The unsupervised clustering confirmed similarity of our models to group $3 \mathrm{MB}$ and also most substantial matches to groups $3 \beta$ and $3 \gamma$ (fig. S5E). This is consistent with the observation of GFI1 activation to be restricted to group $3 \beta$ samples and MYC amplification in group $3 \gamma$. Nevertheless, MYC expression levels in group $3 \beta$ are comparable to those in group $3 \gamma$ (fig. S5F). We also checked the levels of expression of the key components of the NOTCH signaling pathway among the molecular subtypes of group 3/4 MB. We observed only a slight enrichment of NOTCH pathway genes expression in group $3 \gamma$, while group $3 \beta$ demonstrated an opposite effect (fig. S5G). This suggests that NOTCH pathway might play a pivotal role in the initial steps of tumor formation. To study the effects of N1ICD on Math $1^{+}$progenitors, we checked the transfected cerebella 14 days after injection: we found that N1ICD + MYC/Gfi1-transfected cells already formed small clusters of $\mathrm{Ki}^{+} 7^{+}$ cells in the EGL, unlike granule neuron progenitors transfected with N1ICD alone (fig. S5, $\mathrm{H}$ to $\mathrm{K}$ ).

To confirm that N1ICD is required for the first steps of MB formation, we transfected Math $1^{+}$cells with $M Y C / G f i 1$ and a nonintegrating plasmid encoding for N1ICD, allowing the transient expression of the transgene. As shown in Fig. 5F, transient expression of N1ICD was sufficient to allow tumor formation driven by MYC/Gfil overexpression in 7 of 28 mice (Fig. 5, A and B). These tumors are $\mathrm{GFAP}^{-}$and $\mathrm{pH}^{+}$(fig. $\mathrm{S} 6, \mathrm{~A}$ and $\mathrm{B}$ ), resembling human group $3 \mathrm{MB}$ and other published group $3 \mathrm{MB}$ mouse models. Notably, the activity of N1ICD is sufficient during early phases of tumor formation, while being not essential for its progression. Expression of V5-tagged N1ICD is detectable in tumors driven by MYC/ Gfil + N1ICD stable, whereas it is not maintained in tumors generated by transient N1ICD expression (Fig. 5G). To confirm that the activation of the Notch pathway is not required for the tumor progression, we checked the expression levels of known Notch pathway genes in our tumors (fig. S6C). We did not detect any up-regulation of Notch pathway genes (Hes1, Hes5, Jag1, and Notch1) in tumors driven by MYC/Gfil (under the control of $S 100 \mathrm{~b}$ promoter), suggesting that fully grown tumors do not rely on the Notch pathway for their sustenance. Notch pathway genes, such as Hes5 and Jag1, were overexpressed only in tumors stably expressing N1ICD together with MYC/Gfil in Math1 ${ }^{+}$cells. Last, we tested the effect of Notch1 activation in Sox $2^{+}$progenitors as well. Notably, MYC/ Gfil + N1ICD overexpression in Sox $2^{+}$cells induces MB in 9 of 11 mice (fig. S6D). Overall, our data suggest that Notch pathway plays a critical role in group $3 \mathrm{MB}$ initiation and formation in various cerebellar progenitors, such as $\mathrm{S} 00 \mathrm{~b}^{+}, \mathrm{Math}^{+}$, and Sox $2^{+}$cells.

\section{DISCUSSION}

Despite large effort in understanding the cell of origin of different tumors, the relationship of the contribution of the cell of origin versus the relevant driver mutations is still elusive. Current opinion in the field is that tumor identity can be defined by the cell of origin and/or genetic mutation $(1,2)$. In the first scenario, the cells of origin have specific features, such as the epigenetic state, that make them competent in inducing cancer and may also direct cell tumor-initiating 
A

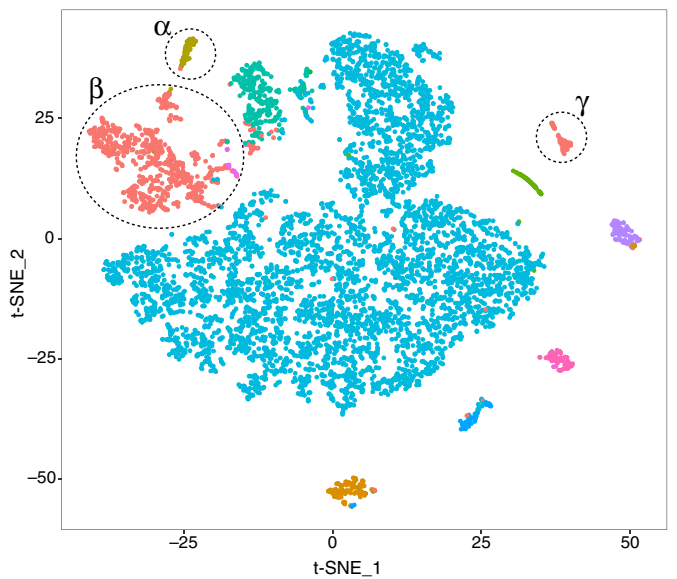

\begin{tabular}{|l|}
\hline Astrocytes \\
Blood vessel \\
Ciliated cells \\
Erythrocyte \\
GABA progenitor \\
GABAergic interneuron \\
Granule \\
Meninges/Pia membrane \\
Microglia \\
Progenitor \\
Purkinje
\end{tabular}

B

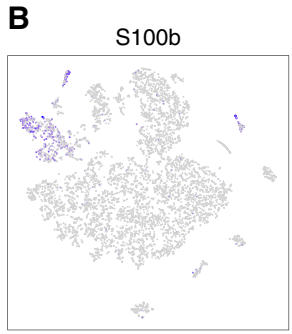

C

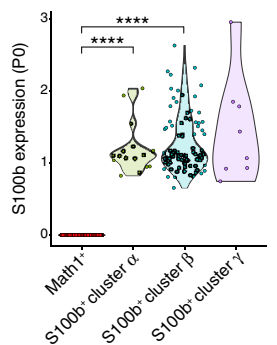

D

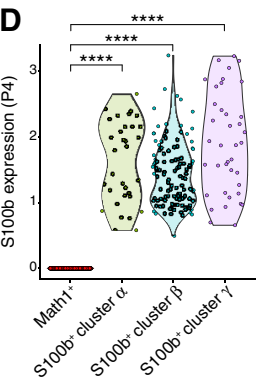

E

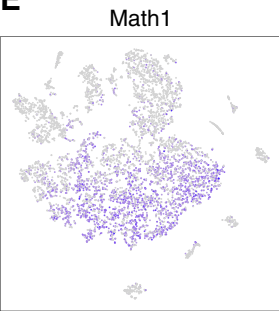

F

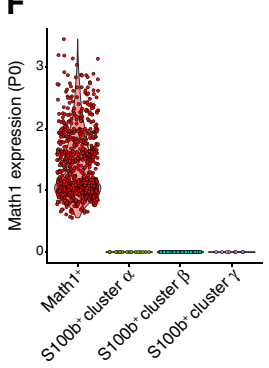

G

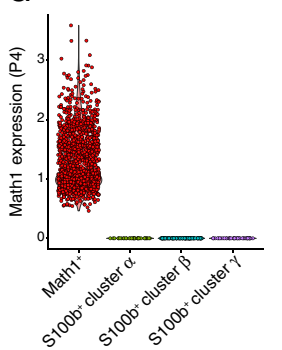

H

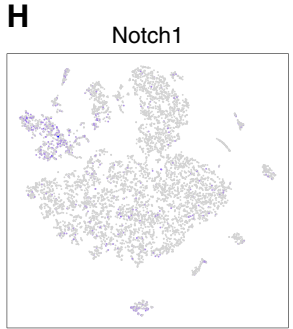

I

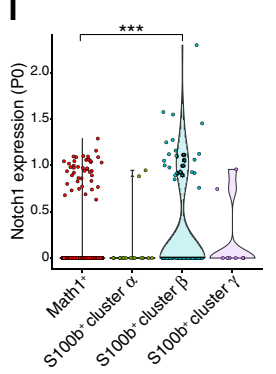

J

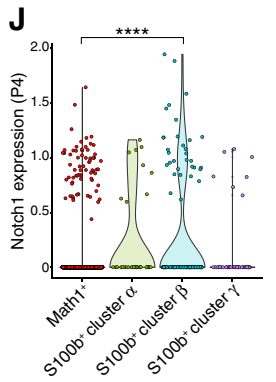

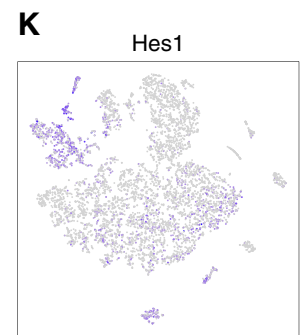
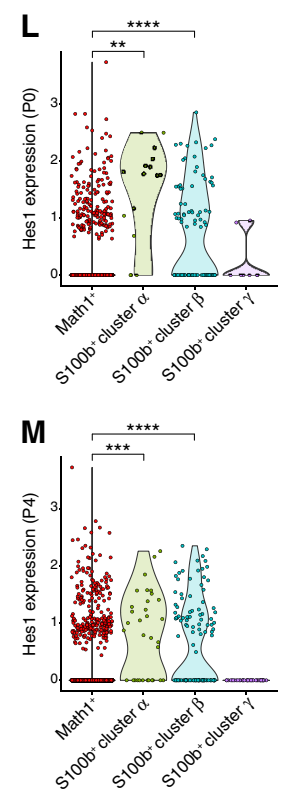

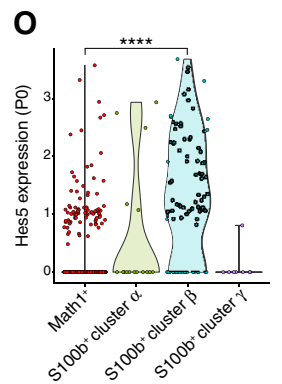

N

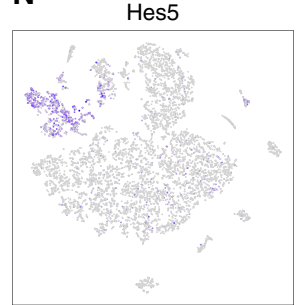

P

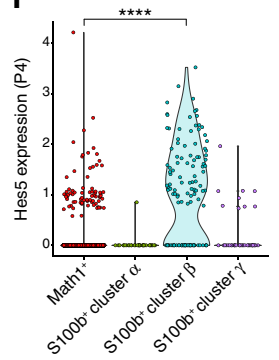

Fig. 4. Notch pathway expression in the mouse postnatal cerebellum. (A) t-distributed stochastic neighbor embedding (t-SNE) visualization of cerebellar derived cell clusters at P0 and P4. Each point represents one cell. Main clusters are marked in color, while relevant subclusters are labeled as $\alpha, \beta$, and $\gamma$. GABA, $\gamma$-aminobutyric acid. ( $B$ to $P$ ) scRNA-seq analysis of cell type specific markers in different cell clusters. (B, E, H, K, and N) t-SNE visualization showing expression of cell type-specific markers: S100b (B), Math1 (E), Notch1 (H), Hes1 (K), Hes5 (N). Cells are color-coded according to genes expression. (C, F, I, L, and O) Violin plots to visualize gene expression levels of S100b (C), Math1 (F), Notch1 (I), Hes1 (L), and Hes5 (O) at P0 in four groups: mutually exclusive Math $1^{+}$cells and S100b ${ }^{+}$cells within cluster $\alpha$, S100b ${ }^{+}$cells within cluster $\beta$, and S100 b cells within cluster $\gamma .(\mathrm{D}, \mathrm{G}, \mathrm{J}, \mathrm{M}$, and P) Violin plots to visualize gene expression levels of S100b (D), Math1 (G), Notch1 (J), Hes1 (M), and Hes5 (P) at P4 in four groups: mutually exclusive Math $1^{+}$cells and S100b ${ }^{+}$cells within cluster $\alpha, S 100 \mathrm{~b}^{+}$cells within cluster $\beta$, and S100 $\mathrm{b}^{+}$cells within cluster $\gamma$. Unpaired Student's $t$ test, ${ }^{* *} q<0.01,{ }^{* * *} q<0.001$, and ${ }^{* * * *} q<0.0001$. 
A

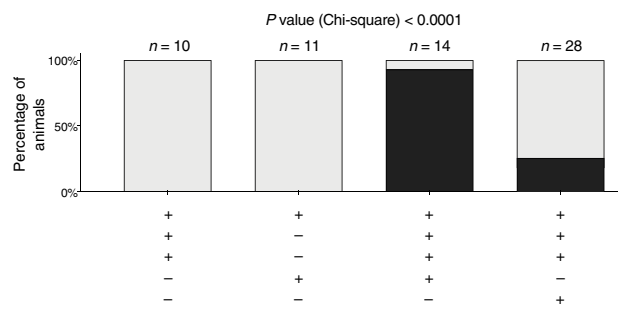

B

MB

$\square$ NoMB

pMath1-cre

pPB-LSL-Myc

PPB-LSL-N1ICD-V5 (stable)

pCAG N1ICD-V5 (transient)

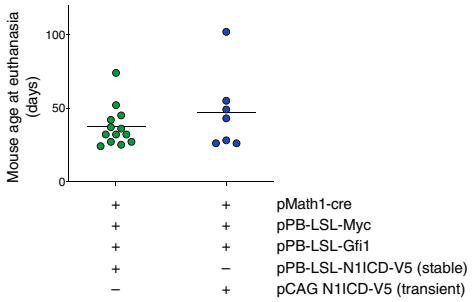

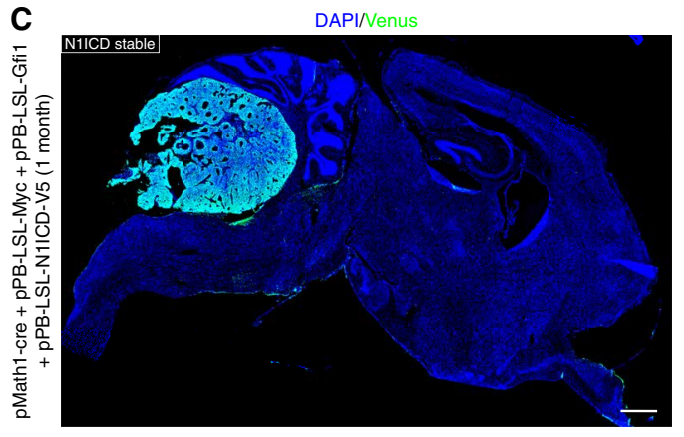

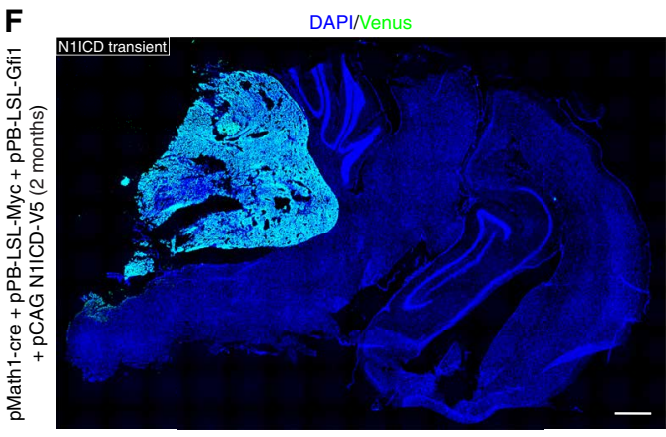

\section{G}

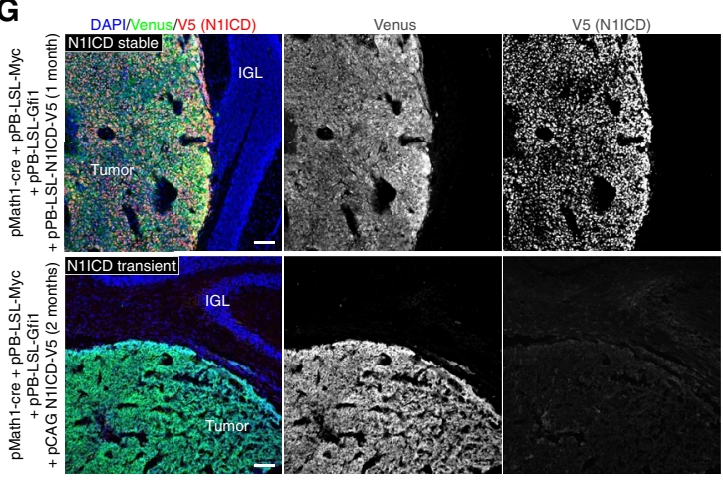

D

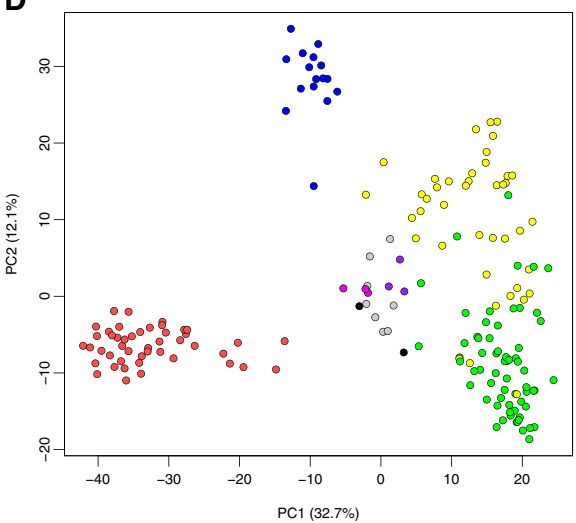

E
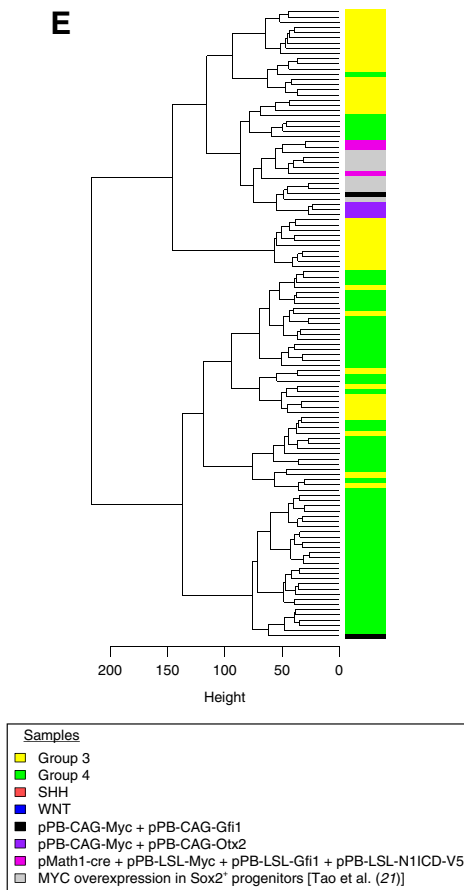

Fig. 5. Notch pathway determines competence to generate Group 3 MB. (A) Histograms show the percentage of mice that develop MB after transfection at $P 0$ with either MYC/Gfi1, or N1ICD, or MYC/Gfi1 + stable N1ICD, or MYC/Gfi1 + transient N1ICD in Math $1^{+}$cells. (B) Plots show the age at which mice where sacrificed due to MB development after transfection at P0 of MYC/Gfi1 with stable or transient N1ICD in Math $1^{+}$cells. Mean is shown in black. (C) Venus immunofluorescence of CD1 mouse brain sagittal section 1 month after transfection of MYC/Gfi1 + stable N1ICD in Math $1^{+}$cells at P0. (D) Principal components analysis visualization based on previously published group 3 MB mouse models (MYC/Gfi1; MYC/Otx2; MYC overexpression in Sox2 $2^{+}$progenitors) $(9,21)$ and tumors developed after transfection of MYC/Gfi1 + stable N1ICD in Math $1^{+}$cells, combined with batch effect adjusted MB ICGC RNA-seq data on top 500 highly variable genes. PC, principal component. (E) Unsupervised hierarchical clustering from the same samples. (F) Venus immunofluorescence of CD1 mouse brain sagittal section 2 months after transfection of MYC/Gfi1 + transient N1ICD in Math $1^{+}$cells at P0. (G) Confocal images of Venus and V5 immunofluorescence of tumors in CD1 mice after transfection of MYC/Gfi1 with stable or transient N1ICD in Math $1^{+}$cells at P0. Chi-square test (A). Scale bars, $1 \mathrm{~mm}(\mathrm{C}$ and F) and $100 \mu \mathrm{m}(\mathrm{G})$. 
capacity. Recent studies have shown that the epigenetic landscape is a critical determinant of both transformation susceptibility and the acquisition of a stem or progenitor fate $(47,48)$. For example, work in zebrafish has shown that the epigenetic state can act as a determining factor for the cell of origin of melanoma (49). On the other hand, in MB tumors, SHH activation produces the same tumors starting from different cells (6-8). Furthermore, in breast cancer, oncogenic insults can change cell fate, and this fate is reflected in the tumor phenotype $(26,27)$. Notably, these oncogenic cues have been modulated in cells that are competent to induce cancer and change their cellular fate before the tumor initiation. It is possible that certain mutations are powerful enough in terms of defining cell fate, being able to override the transcriptional context of the cell of origin. Our work shows that $\mathrm{S} 100 \mathrm{~b}^{+}$cells are competent to induce $\mathrm{MB}$ and that $\mathrm{S} 100 \mathrm{~b}^{+}$cells present high levels of Notch pathway activity. By overexpressing the active Notch1 form (N1ICD), we demonstrated that Notch1 pathway activation, upon MYC/Gfil overexpression, induces cancer in Math $1^{+}$and Sox $2^{+}$cells. Notably, Notch1 overexpression per se is not sufficient to induce cancer in Math $1^{+}$progenitors but requires the overexpression of MYC/Gfil, as in $\mathrm{S} 100 \mathrm{~b}^{+}$cells. Moreover, by transiently overexpressing N1ICD in Math $1^{+}$cells, we showed that Math $1^{+}$progenitors are able to generate group $3 \mathrm{MB}$ upon transient Notch1 pathway activation, which is not required to sustain tumor growth at later time points. We did not observe significant NOTCH pathway activation in human group 3 and $4 \mathrm{MB}$ samples. This could be related to extensive somatic switches from the cells of origin occurring in group $3 \mathrm{MB}$. This hypothesis was partially confirmed by Hovestadt et al. (13) study, where group $3 \mathrm{MB}$ did not demonstrate any clear similarity to mouse cerebellum cell types. Full response to this question, about group 3 subtypes cells of origin, could be achieved in precise comparison to human materials to verify the association in the same species material. In the human cerebellum, S100B is expressed in many neural cell types and progenitors and is less "astrocyte-specific" than GFAP (25), suggesting that considering S100B as an astrocytespecific marker might not be correct. We validated our findings also in human cerebellar organoids, and our experiments clarified that $\mathrm{S} 100 \mathrm{~B}-\mathrm{cre}^{+}$cells are competent to induce hyperproliferation in cerebellar organoids. MB mouse models have been already developed by postnatally deregulating $M y c$ and/or Gfil ex vivo in Math $1^{+}$ and Sox $2^{+}$cells $(11,21)$. Notably, cell dissociation for fluorescenceactivated cell sorting and ex vivo manipulation are able to activate Notch pathway $(50,51)$ and, in light of our data, it appears to be a determinant of cell competence. Therefore, such ex vivo manipulations might result in the acquisition of competence for developing group $3 \mathrm{MB}$ by these $\mathrm{Math}^{+}$and Sox $2^{+}$progenitors, which might not have in vivo Notch activation per se. With our gene transfer technology, we are not able to induce MB from Math $1^{+}$or Sox $2^{+}$cells, unless we ectopically activate the Notch pathway. However, we cannot exclude that the absence of tumors from Sox $2^{+}$cells might be due to the inability of our technical approach to efficiently target the subpopulation of Sox $2^{+}$cells with an active Notch pathway in vivo. We were not able to test the tumorigenic potential of the early Sox $2^{+}$progenitors that have high levels of Notch $(32,33)$ and that might be competent in inducing group $3 \mathrm{MB}$. Together, our data point to the direction that Notch activity, which is physiologically involved in determining progenitor identity in a wide variety of contexts, may be a general regulator of cancer cell of origin competence.

\section{MATERIALS AND METHODS Plasmids}

The plasmid encoding a hyperactive form of the piggyBac transposase [pCMV HAhyPBase (pPBase)] was a gift from the Wellcome Sanger Institute (52). The piggyBac donor plasmids pPB CAG MYC, pPB CAG Gfi1:FLAG-IRES-GFP, pPB CAG Otx2-IRES-GFP, and pPB CAG Venus were previously described (9). These plasmids were used as backbones to insert before the start codon a loxPSTOP-loxP cassette by polymerase chain reaction (PCR), generating respectively pPB CAG LSL MYC, pPB CAG LSL Gfi1:FLAG-IRESGFP, and pPB CAG LSL Venus. The pPB CAG LSL N1ICD:V5IRES-GFP plasmid was generated by substituting Gfi1:FLAG with the PCR-amplified N1ICD:V5 coding sequence derived from pcDNA3-N1ICD-myc (53). The pCAG N1ICD:V5 and pPB CAG N1ICD:V5-IRES-GFP plasmids were generated by cloning the PCR-amplified N1ICD:V5 coding sequence into the pCAG or pPB CAG backbones, respectively. The pPB CAG LSL DN-Maml1IRES-GFP and pPB CAG LSL DN-Rbpj-IRES-GFP plasmids were generated by substituting Gfil:FLAG with the PCR-amplified coding sequence of DN-Mamll or DN-Rbpj. The former was derived from iChr2-Notch Mosaic (Addgene plasmid \#99752), and the latter was amplified from iMb-Notch-Mosaic (Addgene plasmid \#99749). The pPB CAG LSL mCherry plasmid was generated by substituting Venus coding sequence with mCherry cDNA. The pMath1-creER plasmid was a gift from R. Machold (22) and was used to generate the pMath1-cre plasmid by substituting the creER coding sequence with the cre coding sequence. The pTbr2-cre plasmid was a gift from T. Haydar (54). The pSox2-cre plasmid was generated by cloning the cre coding sequence into pGL3-Sox2 (Addgene plasmid \#101761). The pS100b-cre plasmid was generated by substituting the Sox 2 promoter sequence from pSox2-cre with $S 100 \mathrm{~b}$ promoter sequence, which was PCR amplified from pEMS1384 (Addgene plasmid \#29304). The pHes5-d2EGFP plasmid was a gift from R. Kageyama (41).

\section{Mice husbandry}

Rosa26-LSL-MYC (Stock no. 020458), Rosa26-LSL-tdTomato (Stock no. 007908), Math1-creER (Stock no. 007684), Ascl1-creER (Stock no. 012882), and Sox2-creER (Stock no. 017593) were purchased from the Jackson laboratory. CD1 mice were purchased from Charles River Laboratories. Mice were intraperitoneally injected with TMX $(75 \mathrm{mg} / \mathrm{kg})$ at E9.5, E10.5, E13.5, P0, P1, P2, P5, P7, or P9. Animals were sacrificed at E15.5, P4, P7, P10, P14, P21, P30, P75, or at a humane end point as they displayed signs of morbidity (ataxia, weight loss, and ruffled fur). Mice were housed in a certified animal facility in accordance with European Guidelines. The experiments were approved by the Italian Ministry of Health as conforming to the relevant regulatory standards.

\section{In vivo transfection and in utero electroporation}

For in vivo transfection, plasmid DNA and in vivo-jetPEI transfection reagent (Polyplus-transfection) were mixed according to manufacturer's instructions. $\mathrm{pPBase}$ and piggyBac donor plasmids were mixed at a 1:4 ratio. The pPB CAG Venus or pPB CAG LSL Venus plasmids were always cotransfected as a reporter. P0 to P2 mice were anesthetized on ice for $2 \mathrm{~min}$, placed on a stage in a stereotactic apparatus, and medially injected at lambda: -3.6 dorso-ventral: -1.6 with $4 \mu \mathrm{l}$ of transfection mix using a pulled glass capillary and a FemtoJet microinjector (Eppendorf). In utero electroporation was performed at day E15.5 after defining day E0.5 by the observation of a vaginal 
plug. The pregnant female was anesthetized with $2 \%$ isoflurane, and the uterine horns were exposed. After $1 \mu \mathrm{l}$ of solution $(2.5 \mu \mathrm{g} / \mu \mathrm{l})$ of plasmids in sterile saline was injected into the fourth ventricle of CD1 embryos, DNA was transferred using electric square pulses delivered by forceps-like electrodes ( $35 \mathrm{mV}$; pulse, $50 \mathrm{~ms}$; pause, $950 \mathrm{~ms}$; five pulses).

\section{Human group $3 \mathrm{MB}$ and embryonic cerebellum samples}

Human group $3 \mathrm{MB}$ sections from 8- and 28-year-old male patients and cerebellar sections from 22 and 39 GW human embryos have been provided by F. Giangaspero from Department of Radiologic, Oncologic and Anatomo Pathological Sciences, University Sapienza of Rome, Rome, Italy and Istituto di Ricovero e Cura a Carattere Scientifico (IRCCS) Neuromed, Pozzilli, Isernia, Italy. All the information and the procedures to be used for obtaining consent for the use of human materials were included in the research protocols submitted for ethical review. The study protocol received full approval from the local ethics committees (Policlinico Umberto I, Rome; Papa Giovanni XXIII Hospital, Bergamo; and Ospedale Civile Maggiore, Verona), and the subjects or their parents gave written informed consent.

\section{Immunofluorescence and immunohistochemistry}

Mice were intraventricularly perfused with $4 \%$ paraformaldehyde (PFA), and brains were dissected and postfixed overnight in $4 \%$ PFA. Brains were either cryoprotected in $30 \%$ (w/v) sucrose in water and embedded in Frozen Section Compound (Leica, 3801480) or embedded in paraffin (brains were dehydrated with ethanol and then kept sequentially in xylene and paraffin solutions) or otherwise embedded in 5\% agarose. Frozen Section Compound-embedded brains were cryosectioned at 20 to $40 \mu \mathrm{m}$ with a Leica CM1850 UV Cryostat. Paraffin-embedded brains were sectioned using a Leica Microtome at $10 \mu \mathrm{m}$. Agarose-embedded tissues were sectioned using a Leica Vibratome at $100 \mu \mathrm{m}$. Immunofluorescence stainings were performed on glass slides. Blocking and antibody solutions consisted of phosphate-buffered saline supplemented with $3 \%$ goat serum and $0.3 \%$ Triton X-100 (Sigma-Aldrich). Primary antibodies were incubated overnight at $4^{\circ} \mathrm{C}$ and secondary antibodies for 1 hour at room temperature. Nuclei were stained with 4',6-diamidino-2-phenylindole ( $1 \mu \mathrm{g} / \mathrm{ml}$; Sigma-Aldrich). Sections and coverslips were mounted with permanent mounting medium.

Immunohistochemistry stainings were performed on rehydrated paraffin sections. Antigen retrieval was performed by incubating slices for $30 \mathrm{~min}$ in retrieval solution [ $10 \mathrm{mM}$ sodium citrate and $0.5 \%$ Tween $20(\mathrm{v} / \mathrm{v})(\mathrm{pH} \mathrm{6.0)}]$ at $98^{\circ} \mathrm{C}$. Primary antibodies were incubated overnight at $4^{\circ} \mathrm{C}$ and secondary antibodies for 1 hour at room temperature in antibody solution. Avidin-Biotin complex (ABC) solution was used 2 hours at room temperature (VECTASTAIN Elite ABC Kit Standard PK-6100). The sections were incubated with the substrate at room temperature until suitable staining was observed (DAB Peroxidase Substrate Kit, SK-4100). Nuclei were counterstained with hematoxylin.

The used primary antibodies are listed in table S2. A list of secondary antibodies is provided in table S3.

\section{Imaging}

Images were acquired with a Zeiss Axio Imager M2 (Axiocam MRc, Axiocam MRm). Confocal imaging was performed by Leica TCS Sp5 or Leica TCS Sp8. Live imaging was performed on organoids cultured in Ibidi uncoated 96-well black $\mu$-plates (Ibidi, 89621) by Nikon TI2 equipped with Spinning Disc X-light V2. Images were processed using ImageJ software.

\section{Organoids maintenance and modification}

Human iPSCs (ATCC-DYS0100) were maintained in self renewal on a layer of Geltrex (Gibco, A14133-01), in Essential 8 Basal Medium (Gibco, A15169-01) supplemented with E8 Supplement (50X, Gibco A15171-01) and penicillin (100 U/ml)/streptomycin $(100 \mu \mathrm{g} /$ $\mathrm{ml}$ ) (Gibco, 15140-122). All cells were mycoplasma free. iPSCs were dissociated with $0.5 \mathrm{mM}$ EDTA ( $\mathrm{pH}$ 8.0; Invitrogen, 15575-038) for 3 -min incubation to maintain cell clusters. Cerebellar organoids were cultured as previously described $(31,55)$ and were electroporated at 35 days of differentiation protocol with pPBase, pPB CAG LSL Venus, pPB CAG LSL Gfi1:FLAG-IRES-GFP, pPB CAG LSL $\mathrm{MYC}$, and either pS100b-cre or pSox2-cre resuspended in buffer 5 (under patent) (9). For the 24-hour analysis, organoids were electroporated at 35 days of differentiation protocol with pPB CAG LSL Venus and either pS100b-cre or pSox2-cre. Organoids were transferred inside the electroporation cuvettes ( $2 \mathrm{~mm}$; VWR, ECN 7321136), and electroporation was performed with the Gene Pulser XcellTM. Twenty-four hours after electroporation or 39 days after electroporation, they were fixed in $4 \%$ PFA, cryoprotected in 30\% sucrose, and embedded in Frozen Section Compound (Leica, 3801480). Organoids were cryosectioned at $40 \mu \mathrm{m}$ with Thermo Fisher Scientific HM525 NX cryostat.

\section{RNA isolation and quantitative reverse transcription PCR}

The total RNA from murine tissues was extracted with TRIzol reagent (Invitrogen) and reverse-transcribed using an iScript cDNA synthesis kit (BioRad) according to the manufacturer's instructions. Quantitative reverse transcription PCR (qRT-PCR) was performed using Power SYBR Green PCR Master Mix (Applied Biosystems). The results are presented as linearized $C t$ values normalized to the housekeeping gene Gapdh and the indicated reference value $\left(2^{-\Delta \Delta C t}\right)$. Primer sequences used for $\mathrm{qRT}$-PCR are listed as follows:

Gapdh, 5' -TGTGTCCGTCGTGGATCTGA-3' (forward) and 5'-CCTGCTTCACCACCTTCTTGA-3' (reverse); Notch1, 5'-AAGTGGG ACCTGCCTGAATG-3' (forward) and 5'-GATTGGAGTCCTGGCATCGT-3' (reverse); Hes 1, 5' -ACGACACCGGACAAACCAAA- $3^{\prime}$ (forward) and

5' - AATGCCGGGAGCTATCTTTCT-3' (reverse); Hes5, 5' -CCAAGGAGAAAAACCGACTGC-3' (forward) and 5'-GGCT TTGCTGTGTTTCAGGT-3' (reverse); and Jag1, 5' -CGGGGGTAACACCTTCAATCT-3' (forward) and 5' -TCCACCAGCAAAGTGTAGGAC-3' (reverse).

\section{Cell quantification and statistical analysis Cell quantification in P4 CD1 mouse cerebella transfected with pS100b-cre + pPB-LSL-Venus}

Venus ${ }^{+}$cells coming from at least two mice were analyzed for each quantification. In particular, $n=2$ mice, 99 cells (Fig. 2B); $n=5$ mice, 362 cells (Fig. 2C). In Fig. 2D, $n=3$ mice, 99 cells $\left(\right.$ Venus $^{+} / \mathrm{GFAP}^{+}$); $n=7$ mice, 188 cells $\left(\right.$ Venus ${ }^{+} /$Sox $2^{+}$); $n=5$ mice, 81 cells $\left(\right.$ Venus $^{+} /$ Nestin $^{+}$;Venus ${ }^{+} /$Sox $2^{+} /$Nestin $^{+}$; Venus ${ }^{+} /$Sox $2^{-} / \mathrm{Nestin}^{+}$and Venus ${ }^{+} /$ Sox2 $2^{-}$Nestin ${ }^{-}$). All data are presented as means + SEM.

Cell quantification in P4 CD1 mouse cerebella transfected with pS100b-cre + pPB-LSL-mCherry + pHes5-d2EGFP or pMath1-cre + pPB-LSL-mCherry + pHes5-d2EGFP

$\mathrm{Venus}^{+}$cells coming from at least three mice were analyzed for each quantification. All data are presented as means + SEM. Data were compared using an unpaired two-tailed Student's $t$ test. 


\section{Organoids quantitative 24-hour analysis}

Data are presented as means + SEM. For each condition, 10 to 17 organoids were examined and at least 30 to 45 cells were quantified. Live clustering analysis

Brightfield and fluorescence images of the electroporated organoids were acquired, and Venus ${ }^{+}$fluorescent area was quantified using ImageJ. Groups of Venus ${ }^{+}$cells with an area of $\geq 3500 \mu \mathrm{m}^{2}$ were considered clusters.

\section{qRT-PCR analysis}

The Shapiro-Wilk test was used to validate the assumption of normality. Statistical significance was determined using a one-way analysis of variance (ANOVA) with Tukey's post hoc pairwise test for data with normal distribution or using the Kruskal-Wallis test with Dunn's post hoc test for data with non-normal distribution.

\section{RNA extraction, library generation, and sequencing}

Total RNA was extracted from fresh-frozen tumor tissues with TRIzol reagent (Invitrogen). Libraries were prepared from the extracted RNAs using the QuantSeq 3'mRNA-Seq Library Prep Kit-FWD (Lexogen, Vienna, Austria) using 0.5 to $1 \mu \mathrm{g}$ of RNA per library and following the manufacturers' instructions. We modified the standard protocol by adding unique molecular identifiers during the second strand synthesis step. Indices from the Lexogen i7 6nt Index Set and i5 6nt Dual Indexing Add-on Kits (catalog nos. 044.96 and 047.96, Lexogen) were used, and 15 to 19 cycles of library amplification were performed. Libraries were eluted in $30 \mu \mathrm{l}$ of the kit's elution buffer. The double-stranded DNA concentration was quantified using the Qubit dsDNA HS Assay Kit (Thermo Fisher Scientific), ranging from 3 to $12 \mathrm{ng} / \mu \mathrm{l}$. The molar concentration of cDNA molecules in the individual libraries was calculated from the doublestranded DNA concentration and the single library average size (determined on a PerkinElmer LabChip GX). An equal number of cDNA molecules from each library were pooled, and the final pool was purified once more to remove any free primer and prevent index hopping. The pooled libraries were sequenced in a Novaseq 6000 instrument (Illumina, San Diego, CA) on an SP flowcell, producing $900 \mathrm{M}$ single reads [100 nucleotides (nt)] and in a Hiseq2500 (Illumina, San Diego, CA) on a rapid run lane, producing $166 \mathrm{M}$ single reads (100 nt).

Sequencing data: 10.5281/zenodo.4730190, Gene Expression Omnibus (GEO): GSE173888.

\section{Mouse cerebellum scRNA-seq data integration}

The full cell type annotation and the gene expression counts per sample were obtained from the shared materials of the corresponding mice cerebellum single-cell study (40). The samples on time points $\mathrm{P} 0$ and $\mathrm{P} 4$ were combined and reanalyzed using Seurat v2.3.2 package (56). Furthermore, the cells from three selected assigned clusters $\alpha, \beta$, and $\gamma$ were split into groups on the basis of the presence of either Math1 or S100b expression. Afterward, the differential gene expression comparison among these groups $\left(\mathrm{Math}^{+}\right.$versus $\mathrm{S} 100 \mathrm{~b}^{+}$ cluster $\alpha$, Math $1^{+}$versus $S 100 \mathrm{~b}^{+}$cluster $\beta$, and Math $1^{+}$versus $S 100 \mathrm{~b}^{+}$ cluster $\gamma$ ) was performed using $t$ test separately on time points $\mathrm{P} 0$ and P4. Last, adjusted $P$ values were computed using $q$ value R package.

\section{Mouse model gene expression analysis}

The RNA-seq transcripome profiling was performed on the mouse model materials in the corresponding cohorts: pPB-CAG-MYC + pPB-CAG-Gfil $(n=2)$, pPB-CAG-MYC + pPB-CAG-Otx2 $(n=3)$,
pS100b-cre + pPB-LSL-MYC + pPB-LSL-Gfil $(n=3)$, and pMath1cre + pPB-LSL-MYC + pPB-LSL-Gfil + pPB-LSL-N1ICD $(n=3)$. The reads were aligned using STAR v2.4.1 tool (57) to mm10 reference genome, and gene expression counts were computed using featureCounts module of the Subread package v1.4.6 (58) with Ensembl GRCm 38 v72 annotation. The quality control (QC) was performed with Qualimap v2 using RNA-seq QC mode (59). Furthermore, for comparison to human tumors, RNA-seq gene expression data were collected from MB landscape study (38). The orthologous genes common between species were filtered using biomart R package and corresponding Ensembl database annotation. Unsupervised clustering was performed on combined RNA-seq cohorts after ComBat batch effect adjustment (60), with focus on top 500 most highly variable genes (HVGs).

Affymetrix data from Cavalli et al. (46) data study (GEO dataset GSE85218) were integrated on the basis of selection of AffyIds representing the common orthologous genes between mouse and human. Batch effect adjustment was performed via ComBat as it was described for RNA-seq data analysis. Unsupervised clustering results were verified by controlling switch of top HVGs from 500 to 2000 .

\section{MYC/NOTCH pathway expression levels in human groups 3 and $4 M B$}

MYC expression levels in human group 3 and 4 MB were obtained from the GEO dataset GSE85217 (46). Data were analyzed using the R2: Genomics Analysis and Visualization Platform (http://r2.amc. nl). NOTCH pathway genes selection was performed from Kyoto Encyclopedia of Genes and Genomes pathways annotation. Gene expression enrichment estimation across group 3/4 subclasses per sample was performed on the basis of computation of mean expression among gene pathways.

\section{SUPPLEMENTARY MATERIALS}

Supplementary material for this article is available at http://advances.sciencemag.org/cgi/ content/full/7/26/eabd2781/DC1

View/request a protocol for this paper from Bio-protocol.

\section{REFERENCES AND NOTES}

1. P. B. Gupta, I. Pastushenko, A. Skibinski, C. Blanpain, C. Kuperwasser, Phenotypic plasticity: Driver of cancer initiation, progression, and therapy resistance. Cell Stem Cell 24, 65-78 (2019).

2. N. K. Lytle, A. G. Barber, T. Reya, Stem cell fate in cancer growth, progression and therapy resistance. Nat. Rev. Cancer 18, 669-680 (2018).

3. S. Alcantara Llaguno, J. Chen, C. H. Kwon, E. L. Jackson, Y. Li, D. K. Burns, A. Alvarez-Buylla, L. F. Parada, Malignant astrocytomas originate from neural stem/progenitor cells in a somatic tumor suppressor mouse model. Cancer Cell 15, 45-56 (2009).

4. S. R. Alcantara Llaguno, Z. Wang, D. Sun, J. Chen, J. Xu, E. Kim, K. J. Hatanpaa, J. M. Raisanen, D. K. Burns, J. E. Johnson, L. F. Parada, Adult lineage-restricted CNS progenitors specify distinct glioblastoma subtypes. Cancer Cell 28, 429-440 (2015).

5. C. Zhao, J. Blum, A. Chen, H. Y. Kwon, S. H. Jung, J. M. Cook, A. Lagoo, T. Reya, Loss of $\beta$-catenin impairs the renewal of normal and CML stem cells in vivo. Cancer Cell 12, 528-541 (2007).

6. G. Aiello, C. Ballabio, R. Ruggeri, L. Fagnocchi, M. Anderle, I. Morassut, D. Caron, F. Garilli, F. Gianno, F. Giangaspero, S. Piazza, A. Romanel, A. Zippo, L. Tiberi, Truncated BRPF1 cooperates with smoothened to promote adult Shh medulloblastoma. Cell Rep. 29 4036-4052.e10 (2019).

7. Z. J. Yang, T. Ellis, S. L. Markant, T. A. Read, J. D. Kessler, M. Bourboulas, U. Schüller, R. Machold, G. Fishell, D. H. Rowitch, B. J. Wainwright, R. J. Wechsler-Reya, Medulloblastoma can be initiated by deletion of patched in lineage-restricted progenitors or stem cells. Cancer Cell 14, 135-145 (2008).

8. U. Schüller, V. M. Heine, J. Mao, A. T. Kho, A. K. Dillon, Y. G. Han, E. Huillard, T. Sun, A. H. Ligon, Y. Qian, Q. Ma, A. Alvarez-Buylla, A. P. McMahon, D. H. Rowitch, K. L. Ligon, Acquisition of granule neuron precursor identity is a critical determinant of progenitor cell competence to form shh-induced medulloblastoma. Cancer Cell 14, 123-134 (2008). 
9. C. Ballabio, M. Anderle, M. Gianesello, C. Lago, E. Miele, M. Cardano, G. Aiello, S. Piazza, D. Caron, F. Gianno, A. Ciolfi, L. Pedace, A. Mastronuzzi, M. Tartaglia, F. Locatelli, E. Ferretti, F. Giangaspero, L. Tiberi, Modeling medulloblastoma in vivo and with human cerebellar organoids. Nat. Commun. 11, 583 (2020).

10. P. A. Northcott, C. Lee, T. Zichner, A. M. Stütz, S. Erkek, D. Kawauchi, D. J. H. Shih, V. Hovestadt, M. Zapatka, D. Sturm, D. T. W. Jones, M. Kool, M. Remke, F. M. G. Cavalli, S. Zuyderduyn, G. D. Bader, S. Vandenberg, L. A. Esparza, M. Ryzhova, W. Wang, A. Wittmann, S. Stark, L. Sieber, H. Seker-Cin, L. Linke, F. Kratochwil, N. Jäger, I. Buchhalter, C. D. Imbusch, G. Zipprich, B. Raeder, S. Schmidt, N. Diessl, S. Wolf, S. Wiemann, B. Brors, C. Lawerenz, J. Eils, H. J. Warnatz, T. Risch, M. L. Yaspo, U. D. Weber, C. C. Bartholomae, C. Von Kalle, E. Turányi, P. Hauser, E. Sanden, A. Darabi, P. Siesjö, J. Sterba, K. Zitterbart, D. Sumerauer, P. Van Sluis, R. Versteeg, R. Volckmann, J. Koster, M. U. Schuhmann, M. Ebinger, H. L. Grimes, G. W. Robinson, A. Gajjar, M. Mynarek, K. Von Hoff, S. Rutkowski, T. Pietsch, W. Scheurlen, J. Felsberg, G. Reifenberger, A. E. Kulozik, A. Von Deimling, O. Witt, R. Eils, R. J. Gilbertson, A. Korshunov, M. D. Taylor, P. Lichter, J. O. Korbel, R. J. Wechsler-Reya, S. M. Pfister, Enhancer hijacking activates GFI1 family oncogenes in medulloblastoma. Nature 511, 428-434 (2014).

11. D. Kawauchi, G. Robinson, T. Uziel, P. Gibson, J. Rehg, C. Gao, D. Finkelstein, C. Qu, S. Pounds, D. W. Ellison, R. J. Gilbertson, M. F. Roussel, A mouse model of the most aggressive subgroup of human medulloblastoma. Cancer Cell 21, 168-180 (2012).

12. Y. Pei, C. E. Moore, J. Wang, A. K. Tewari, A. Eroshkin, Y. J. Cho, H. Witt, A. Korshunov, T. A. Read, J. L. Sun, E. M. Schmitt, C. R. Miller, A. F. Buckley, R. E. McLendon, T. F. Westbrook, P. A. Northcott, M. D. Taylor, S. M. Pfister, P. G. Febbo, R. J. Wechsler-Reya, An animal model of MYC-driven medulloblastoma. Cancer Cell 21, 155-167 (2012).

13. V. Hovestadt, K. S. Smith, L. Bihannic, M. G. Filbin, M. K. L. Shaw, A. Baumgartner, J. C. DeWitt, A. Groves, L. Mayr, H. R. Weisman, A. R. Richman, M. E. Shore, L. Goumnerova, C. Rosencrance, R. A. Carter, T. N. Phoenix, J. L. Hadley, Y. Tong, J. Houston, R. A. Ashmun, M. DeCuypere, T. Sharma, D. Flasch, A. Silkov, K. L. Ligon, S. L. Pomeroy, M. N. Rivera, O. Rozenblatt-Rosen, J. M. Rusert, R. J. Wechsler-Reya, X. N. Li, A. Peyrl, J. Gojo, D. Kirchhofer, D. Lötsch, T. Czech, C. Dorfer, C. Haberler, R. Geyeregger, A. Halfmann, C. Gawad, J. Easton, S. M. Pfister, A. Regev, A. Gajjar, B. A. Orr, I. Slavc, G. W. Robinson, B. E. Bernstein, M. L. Suvà, P. A. Northcott, Resolving medulloblastoma cellular architecture by single-cell genomics. Nature 572, 74-79 (2019).

14. M. C. Vladoiu, I. El-Hamamy, L. K. Donovan, H. Farooq, B. L. Holgado, Y. Sundaravadanam, V. Ramaswamy, L. D. Hendrikse, S. Kumar, S. C. Mack, J. J. Y. Lee, V. Fong, K. Juraschka, D. Przelicki, A. Michealraj, P. Skowron, B. Luu, H. Suzuki, A. S. Morrissy, F. M. G. Cavalli, L. Garzia, C. Daniels, X. Wu, M. A. Qazi, S. K. Singh, J. A. Chan, M. A. Marra, D. Malkin, P. Dirks, L. Heisler, T. Pugh, K. Ng, F. Notta, E. M. Thompson, C. L. Kleinman, A. L. Joyner, N. Jabado, L. Stein, M. D. Taylor, Childhood cerebellar tumours mirror conserved fetal transcriptional programs. Nature 572, 67-73 (2019).

15. P. Haldipur, K. A. Aldinger, S. Bernardo, M. Deng, A. E. Timms, L. M. Overman, C. Winter, S. N. Lisgo, F. Razavi, E. Silvestri, L. Manganaro, H. Adle-Biasette, F. Guilmiot, R. Russo, D. Kidron, P. R. Hof, D. Gerrelli, S. J. Lindsay, W. B. Dobyns, I. A. Glass, P. Alexandre, K. J. Millen, Spatiotemporal expansion of primary progenitor zones in the developing human cerebellum. Science 366, 454-460 (2019).

16. D. C. Van Essen, Surface-based atlases of cerebellar cortex in the human, macaque, and mouse. Ann. N. Y. Acad. Sci. 978, 468-479 (2002).

17. T. Butts, M. J. Green, R. J. T. Wingate, Development of the cerebellum: Simple steps to make a "little brain". Development 141, 4031-4041 (2014).

18. B. T. Vo, J. A. Kwon, C. Li, D. Finkelstein, B. Xu, B. A. Orr, C. J. Sherr, M. F. Roussel, Mouse medulloblastoma driven by CRISPR activation of cellular Myc. Sci. Rep. 8, 8733 (2018),

19. C. Lee, V. A. Rudneva, S. Erkek, M. Zapatka, L. Q. Chau, S. K. Tacheva-Grigorova, A. Garancher, J. M. Rusert, O. Aksoy, R. Lea, H. P. Mohammad, J. Wang, W. A. Weiss, H. L. Grimes, S. M. Pfister, P. A. Northcott, R. J. Wechsler-Reya, Lsd1 as a therapeutic target in Gfi1-activated medulloblastoma. Nat. Commun. 10, 332 (2019).

20. B. T. Vo, C. Li, M. A. Morgan, I. Theurillat, D. Finkelstein, S. Wright, J. Hyle, S. M. C. Smith, Y. Fan, Y.-D. Wang, G. Wu, B. A. Orr, P. A. Northcott, A. Shilatifard, C. J. Sherr, M. F. Roussel, Inactivation of Ezh2 upregulates Gfi1 and drives aggressive Myc-driven group 3 medulloblastoma. Cell Rep. 18, 2907-2917 (2017).

21. R. Tao, N. Murad, Z. Xu, P. Zhang, K. Okonechnikov, M. Kool, S. Rivero-Hinojosa, C. Lazarski, P. Zheng, Y. Liu, C. G. Eberhart, B. R. Rood, R. Packer, Y. Pei, MYC drives group 3 medulloblastoma through transformation of Sox $2^{+}$astrocyte progenitor cells. Cancer Res. 79, 1967-1980 (2019).

22. R. MacHold, G. Fishell, Math1 is expressed in temporally discrete pools of cerebellar rhombic-lip neural progenitors. Neuron 48, 17-24 (2005).

23. K. Arnold, A. Sarkar, M. A. Yram, J. M. Polo, R. Bronson, S. Sengupta, M. Seandel, N. Geijsen, K. Hochedlinger, Sox $2^{+}$adult stem and progenitor cells are important for tissue regeneration and survival of mice. Cell Stem Cell 9, 317-329 (2011).

24. A. Sudarov, R. K. Turnbull, E. J. Kim, M. Lebel-Potter, F. Guillemot, A. L. Joyner, Ascl1 genetics reveals insights into cerebellum local circuit assembly. J. Neurosci. 31, 11055-11069 (2011).
25. J. Steiner, H. G. Bernstein, H. Bielau, A. Berndt, R. Brisch, C. Mawrin, G. Keilhoff, B. Bogerts, Evidence for a wide extra-astrocytic distribution of $\mathrm{S} 100 \mathrm{~B}$ in human brain. BMC Neurosci. 8, 2 (2007).

26. T. A. Proia, P. J. Keller, P. B. Gupta, I. Klebba, A. D. Jones, M. Sedic, H. Gilmore, N. Tung, S. P. Naber, S. Schnitt, E. S. Lander, C. Kuperwasser, Genetic predisposition directs breast cancer phenotype by dictating progenitor cell fate. Cell Stem Cell 8, 149-163 (2011).

27. A. Van Keymeulen, M. Y. Lee, M. Ousset, S. Brohée, S. Rorive, R. R. Giraddi, A. Wuidart, G. Bouvencourt, C. Dubois, I. Salmon, C. Sotiriou, W. A. Phillips, C. Blanpain, Reactivation of multipotency by oncogenic PIK3CA induces breast tumour heterogeneity. Nature $\mathbf{5 2 5}$, 119-123 (2015).

28. D. Kawauchi, R. J. Ogg, L. Liu, D. J. H. Shih, D. Finkelstein, B. L. Murphy, J. E. Rehg, A. Korshunov, C. Calabrese, F. Zindy, T. Phoenix, Y. Kawaguchi, J. Gronych, R. J. Gilbertson, P. Lichter, A. Gajjar, M. Kool, P. A. Northcott, S. M. Pfister, M. F. Roussel, Novel MYC-driven medulloblastoma models from multiple embryonic cerebellar cells. Oncogene 36, 5231-5242 (2017)

29. J. Wang, D. M. Merino, N. Light, B. L. Murphy, Y. D. Wang, X. Guo, A. P. Hodges, L. Q. Chau, K. W. Liu, G. Dhall, S. Asgharzadeh, E. N. Kiehna, R. J. Shirey, K. D. Janda, M. D. Taylor, D. Malkin, D. W. Ellison, S. R. VandenBerg, C. G. Eberhart, R. C. Sears, M. F. Rousse, R. J. Gilbertson, R. J. Wechsler-Reya, Myc and loss of p53 cooperate to drive formation of choroid plexus carcinoma. Cancer Res. 79, 2208-2219 (2019).

30. S. Hachem, A. S. Laurenson, J. P. Hugnot, C. Legraverend, Expression of S100B during embryonic development of the mouse cerebellum. BMC Dev. Biol. 7, 17 (2007).

31. K. Muguruma, A. Nishiyama, H. Kawakami, K. Hashimoto, Y. Sasai, Self-organization of polarized cerebellar tissue in 3D culture of human pluripotent stem cells. Cell Rep. 10, 537-550 (2015).

32. R. P. Machold, D. J. Kittell, G. J. Fishell, Antagonism between Notch and bone morphogenetic protein receptor signaling regulates neurogenesis in the cerebellar rhombic lip. Neural Dev. 2, 5 (2007).

33. T. Zhang, T. Liu, N. Mora, J. Guegan, M. Bertrand, X. Contreras, A. Hansen, C. Streicher, M. Anderle, L. Tiberi, S. Hippenmeyer, B. A. Hassan, Generation of excitatory and inhibitory neurons from common progenitors via Notch signaling in the cerebellum. bioRxiv 10.1101/2020.03.18.997205, (2021).

34. X. Fan, I. Mikolaenko, I. Elhassan, X. Z. Ni, Y. Wang, D. Ball, D. J. Brat, A. Perry, C. G. Eberhart, Notch1 and Notch2 have opposite effects on embryonal brain tumor growth. Cancer Res. 64, 7787-7793 (2004).

35. B. A. Hatton, E. H. Villavicencio, J. Pritchard, M. Leblanc, S. Hansen, M. Ulrich, S. Ditzler, B. Pullar, M. R. Stroud, J. M. Olson, Notch signaling is not essential in sonic hedgehogactivated medulloblastoma. Oncogene 29, 3865-3872 (2010).

36. E. Julian, R. K. Dave, J. P. Robson, A. R. Hallahan, B. J. Wainwright, Canonical Notch signaling is not required for the growth of Hedgehog pathway-induced medulloblastoma. Oncogene 29, 3465-3476 (2010).

37. S. Natarajan, Y. Li, E. E. Miller, D. J. Shih, M. D. Taylor, T. M. Stearns, R. T. Bronson, S. L. Ackerman, J. K. Yoon, K. Yun, Notch1-induced brain tumor models the sonic hedgehog subgroup of human medulloblastoma. Cancer Res. 73, 5381-5390 (2013).

38. P. A. Northcott, I. Buchhalter, A. S. Morrissy, V. Hovestadt, J. Weischenfeldt, T. Ehrenberger, S. Gröbner, M. Segura-Wang, T. Zichner, V. A. Rudneva, H. J. Warnatz, N. Sidiropoulos, A. H. Phillips, S. Schumacher, K. Kleinheinz, S. M. Waszak, S. Erkek, D. T. W. Jones, B. C. Worst, M. Kool, M. Zapatka, N. Jäger, L. Chavez, B. Hutter, M. Bieg, N. Paramasivam, M. Heinold, Z. Gu, N. Ishaque, C. Jäger-Schmidt, C. D. Imbusch, A. Jugold, D. Hübschmann, T. Risch, V. Amstislavskiy, F. G. R. Gonzalez, U. D. Weber, S. Wolf, G. W. Robinson, X. Zhou, G. Wu, D. Finkelstein, Y. Liu, F. M. G. Cavalli, B. Luu, V. Ramaswamy, X. Wu, J. Koster, M. Ryzhova, Y. J. Cho, S. L. Pomeroy, C. Herold-Mende, M. Schuhmann, M. Ebinger, L. M. Liau, J. Mora, R. E. McLendon, N. Jabado, T. Kumabe, E. Chuah, Y. Ma, R. A. Moore, A. J. Mungall, K. L. Mungall, N. Thiessen, K. Tse, T. Wong, S. J. M. Jones, O. Witt, T. Milde, A. Von Deimling, D. Capper, A. Korshunov, M. L. Yaspo, R. Kriwacki, A. Gajjar, J. Zhang, R. Beroukhim, E. Fraenkel, J. O. Korbel, B. Brors, M. Schlesner, R. Eils, M. A. Marra, S. M. Pfister, M. D. Taylor, P. Lichter, The whole-genome landscape of medulloblastoma subtypes. Nature 547, 311-317 (2017).

39. S. A. Kahn, X. Wang, R. T. Nitta, S. Gholamin, J. Theruvath, G. Hutter, T. D. Azad, L. Wadi, S. Bolin, V. Ramaswamy, R. Esparza, K. W. Liu, M. Edwards, F. J. Swartling, D. Sahoo, G. Li, R. J. Wechsler-Reya, J. Reimand, Y. J. Cho, M. D. Taylor, I. L. Weissman, S. S. Mitra, S. H. Cheshier, Notch1 regulates the initiation of metastasis and self-renewal of Group 3 medulloblastoma. Nat. Commun. 9, 4121 (2018).

40. R. A. Carter, L. Bihannic, C. Rosencrance, J. L. Hadley, Y. Tong, T. N. Phoenix, S. Natarajan, J. Easton, P. A. Northcott, C. Gawad, A single-cell transcriptional atlas of the developing murine cerebellum. Curr. Biol. 28, 2910-2920.e2 (2018).

41. T. Ohtsuka, I. Imayoshi, H. Shimojo, E. Nishi, R. Kageyama, S. K. McConnell, Visualization of embryonic neural stem cells using Hes promoters in transgenic mice. Mol. Cell. Neurosci. 31, 109-122 (2006).

42. L. Tiberi, J. Van Den Ameele, J. Dimidschstein, J. Piccirilli, D. Gall, A. Herpoel, A. Bilheu, J. Bonnefont, M. lacovino, M. Kyba, T. Bouschet, P. Vanderhaeghen, BCL6 controls 
neurogenesis through Sirt1-dependent epigenetic repression of selective Notch targets. Nat. Neurosci. 15, 1627-1635 (2012).

43. R. Kopan, M. X. G. llagan, The canonical notch signaling pathway: Unfolding the activation mechanism. Cell 137, 216-233 (2009).

44. A. P. Weng, Y. Nam, M. S. Wolfe, W. S. Pear, J. D. Griffin, S. C. Blacklow, J. C. Aster, Growth suppression of Pre-T acute lymphoblastic leukemia cells by inhibition of notch signaling. Mol. Cell. Biol. 23, 655-664 (2003).

45. C. Blanpain, W. E. Lowry, H. A. Pasolli, E. Fuchs, Canonical notch signaling functions as a commitment switch in the epidermal lineage. Genes Dev. 20, 3022-3035 (2006).

46. F. M. G. Cavalli, M. Remke, L. Rampasek, J. Peacock, D. J. H. Shih, B. Luu, L. Garzia, J. Torchia, C. Nor, A. S. Morrissy, S. Agnihotri, Y. Y. Thompson, C. M. Kuzan-Fischer, H. Farooq, K. Isaev, C. Daniels, B.-K. Cho, S.-K. Kim, K.-C. Wang, J. Y. Lee, W. A. Grajkowska, M. Perek-Polnik, A. Vasiljevic, C. Faure-Conter, A. Jouvet, C. Giannini, A. A. N. Rao, K. K. W. Li, H. K. Ng, C. G. Eberhart, I. F. Pollack, R. L. Hamilton, G. Y. Gillespie, J. M. Olson, S. Leary, W. A. Weiss, B. Lach, L. B. Chambless, R. C. Thompson, M. K. Cooper, R. Vibhakar, P. Hauser, M. L. C. van Veelen, J. M. Kros, P. J. French, Y. S. Ra, T. Kumabe, E. López-Aguilar, K. Zitterbart, J. Sterba, G. Finocchiaro, M. Massimino, E. G. Van Meir, S. Osuka, T. Shofuda, A. Klekner, M. Zollo, J. R. Leonard, J. B. Rubin, N. Jabado, S. Albrecht, J. Mora, T. E. Van Meter, S. Jung, A. S. Moore, A. R. Hallahan, J. A. Chan, D. P. C. Tirapelli, C. G. Carlotti, M. Fouladi, J. Pimentel, C. C. Faria, A. G. Saad, L. Massimi, L. M. Liau, H. Wheeler, H. Nakamura, S. K. Elbabaa, M. Perezpeña-Diazconti, F. C. P. de León, S. Robinson, M. Zapotocky, A. Lassaletta, A. Huang, C. E. Hawkins, U. Tabori, E. Bouffet, U. Bartels, P. B. Dirks, J. T. Rutka, G. D. Bader, J. Reimand, A. Goldenberg, V. Ramaswamy, M. D. Taylor, Intertumoral heterogeneity within medulloblastoma subgroups. Cancer Cell 31, 737-754.e6 (2017).

47. W. Xie, I. Kagiampakis, L. Pan, Y. W. Zhang, L. Murphy, Y. Tao, X. Kong, B. Kang, L. Xia, F. L. F. Carvalho, S. Sen, R. W. Chiu Yen, C. A. Zahnow, N. Ahuja, S. B. Baylin, H. Easwaran, DNA methylation patterns separate senescence from transformation potential and indicate cancer risk. Cancer Cell 33, 309-321.e5 (2018).

48. Y. Yu, K. Schleich, B. Yue, S. Ji, P. Lohneis, K. Kemper, M. R. Silvis, N. Qutob, E. van Rooijen, M. Werner-Klein, L. Li, D. Dhawan, S. Meierjohann, M. Reimann, A. Elkahloun, S. Treitschke, B. Dörken, C. Speck, F. A. Mallette, L. I. Zon, S. L. Holmen, D. S. Peeper, Y. Samuels, C. A. Schmitt, S. Lee, Targeting the senescence-overriding cooperative activity of structurally unrelated H3K9 demethylases in melanoma. Cancer Cell 33, 322-336.e8 (2018).

49. C. K. Kaufman, C. Mosimann, Z. P. Fan, S. Yang, A. J. Thomas, J. Ablain, J. L. Tan, R. D. Fogley E. Van Rooijen, E. J. Hagedorn, C. Ciarlo, R. M. White, D. A. Matos, A. C. Puller, C. Santoriello, E. C. Liao, R. A. Young, L. I. Zon, A zebrafish melanoma model reveals emergence of neural crest identity during melanoma initiation. Science 351, aad2197 (2016).

50. M. D. Rand, L. M. Grimm, S. Artavanis-Tsakonas, V. Patriub, S. C. Blacklow, J. Sklar, J. C. Aster, Calcium depletion dissociates and activates heterodimeric notch receptors. Mol. Cell. Biol. 20, 1825-1835 (2000).

51. W. Liu, K. M. Morgan, S. R. Pine, Activation of the Notch1 stem cell signaling pathway during routine cell line subculture. Front. Oncol. 4, 211 (2014).

52. K. Yusa, L. Zhou, M. A. Li, A. Bradley, N. L. Craig, A hyperactive piggyBac transposase for mammalian applications. Proc. Natl. Acad. Sci. U.S.A. 108, 1531-1536 (2011).

53. A. Rustighi, L. Tiberi, A. Soldano, M. Napoli, P. Nuciforo, A. Rosato, F. Kaplan, A. Capobianco, S. Pece, P. P. Di Fiore, G. Del Sal, The prolyl-isomerase Pin1 is a Notch1 target that enhances Notch1 activation in cancer. Nat. Cell Biol. 11, 133-142 (2009).

54. W. A. Tyler, M. Medalla, T. Guillamon-Vivancos, J. I. Luebke, T. F. Haydar, Neural precursor lineages specify distinct neocortical pyramidal neuron types. J. Neurosci. 35, 6142-6152 (2015).
55. Y. Ishida, H. Kawakami, H. Kitajima, A. Nishiyama, Y. Sasai, H. Inoue, K. Muguruma, Vulnerability of purkinje cells generated from spinocerebellar ataxia Type 6 patientderived iPSCs. Cell Rep. 17, 1482-1490 (2016).

56. A. Butler, P. Hoffman, P. Smibert, E. Papalexi, R. Satija, Integrating single-cell transcriptomic data across different conditions, technologies, and species. Nat. Biotechnol. 36, 411-420 (2018).

57. A. Dobin, T. R. Gingeras, Optimizing RNA-seq mapping with STAR. Methods Mol. Biol. 1415, 245-262 (2016).

58. Y. Liao, G. K. Smyth, W. Shi, FeatureCounts: An efficient general purpose program for assigning sequence reads to genomic features. Bioinformatics 30, 923-930 (2014).

59. K. Okonechnikov, A. Conesa, F. García-Alcalde, Qualimap 2: Advanced multi-sample quality control for high-throughput sequencing data. Bioinformatics 32, 292-294 (2016).

60. J. T. Leek, W. E. Johnson, H. S. Parker, A. E. Jaffe, J. D. Storey, The SVA package for removing batch effects and other unwanted variation in high-throughput experiments. Bioinformatics 28, 882-883 (2012).

Acknowledgments: We thank A. Quattrone, A. Soldano, and members of $\mathrm{CIBIO}$ for helpful discussions, and G. Del Sal and A. Rustighi for the pcDNA3- N1ICD-myc. We thank L. Fava and M. Burigotto for the V5 antibody. The pMath1-creER plasmid was a gift from R. Machold. We thank S. Robbiati (MOF facility) for supporting the work with mice models, and V. De Sanctis and R. Bertorelli (NGS facility) for library generation and sequencing. Funding: This work was funded by a grant from The Giovanni Armenise-Harvard Foundation (Career Development Award), My First AIRC Grant and CARITRO (to L.T.), program "Investissements d'avenir" ANR-10-IAIHU-06, the ICM foundation, Allen Distinguished Investigator Award, and the Roger De Spoelberch Prize (to B.A.H.). M.G. is supported by a doctoral fellowship funded by Fondazione Pezcoller. F.A. is funded by Fondazione Umberto Veronesi postdoctoral fellowship (il Dono di Rossana) and Marie Curie fellowship (844677). T.Z. is supported by doctoral fellowships from the China Scholarship Council. Author contributions: C.B., M.G., and G.A. performed in vivo experiments. C.L. and M.A. performed organoids experiments and live imaging. F.A. performed live imaging. C.B., M.G., and L.T. designed and analyzed all experiments and wrote the manuscript. F. Giang and F. Giann provided the human cerebellar tissue. T.Z. performed the lineage tracing experiments with Sox2-creER mice at E10.5 supervised by B.A.H. K.O. analyzed the mouse cerebellar scRNA-seq data and the tumor RNA-seq data supervised by S.M.P. C.B. created Fig. 1 ( $A$ and $B$ ) and fig. S2F. Competing interests: The authors declare that they have no competing interests. Data and materials availability: All data needed to evaluate the conclusions in the paper are present in the paper and/or the Supplementary Materials. Additional data related to this paper may be requested from the authors.

Submitted 11 June 2020

Accepted 7 May 2021

Published 23 June 2021

$10.1126 /$ sciadv.abd2781

Citation: C. Ballabio, M. Gianesello, C. Lago, K. Okonechnikov, M. Anderle, G. Aiello, F. Antonica, T. Zhang, F. Gianno, F. Giangaspero, B. A. Hassan, S. M. Pfister, L. Tiberi, Notch1 switches progenitor competence in inducing medulloblastoma. Sci. Adv. 7, eabd2781 (2021). 


\section{ScienceAdvances}

\section{Notch1 switches progenitor competence in inducing medulloblastoma}

Claudio Ballabio, Matteo Gianesello, Chiara Lago, Konstantin Okonechnikov, Marica Anderle, Giuseppe Aiello, Francesco Antonica, Tingting Zhang, Francesca Gianno, Felice Giangaspero, Bassem A. Hassan, Stefan M. Pfister and Luca Tiberi

Sci Adv 7 (26), eabd2781.

DOI: $10.1126 /$ sciadv.abd2781

ARTICLE TOOLS

SUPPLEMENTARY MATERIALS

REFERENCES

PERMISSIONS http://advances.sciencemag.org/content/7/26/eabd2781

http://advances.sciencemag.org/content/suppl/2021/06/21/7.26.eabd2781.DC1

This article cites 59 articles, 13 of which you can access for free http://advances.sciencemag.org/content/7/26/eabd2781\#BIBL

http://www.sciencemag.org/help/reprints-and-permissions

Science Advances (ISSN 2375-2548) is published by the American Association for the Advancement of Science, 1200 New York Avenue NW, Washington, DC 20005. The title Science Advances is a registered trademark of AAAS.

Copyright @ 2021 The Authors, some rights reserved; exclusive licensee American Association for the Advancement of Science. No claim to original U.S. Government Works. Distributed under a Creative Commons Attribution NonCommercial License 4.0 (CC BY-NC). 